WALMYR RIBEIRO DE MELLO

\title{
Análise dos fatores que influenciam o desenvolvimento da mucosite oral em transplante de células-tronco hematopoiéticas autólogo
}




\section{Análise dos fatores que influenciam o desenvolvimento da mucosite oral em transplante de células-tronco hematopoiéticas autólogo}

Dissertação apresentada à Faculdade de Medicina da Universidade de São Paulo para obtenção do título de Mestre em Ciências

Programa de: Ciências Médicas

Área de Concentração: Processos Imunes e Infecciosos

Orientador: Prof. Dr. Sergio Paulo Bydlowski

São Paulo

2016 


\section{Dados Internacionais de Catalogação na Publicação (CIP)}

Preparada pela Biblioteca da

Faculdade de Medicina da Universidade de São Paulo

\section{Creprodução autorizada pelo autor}

Mello, Walmyr Ribeiro de

Análise dos fatores que influenciam o desenvolvimento da mucotise oral em transplante de células tronco hematopoiéticas autólogo / Walmyr Ribeiro de Mello. -- São Paulo, 2016.

Dissertação(mestrado)--Faculdade de Medicina da Universidade de São Paulo. Programa de Ciências Médicas. Área de Concentração: Processos Imunes e Infecciosos.

Orientador: Sérgio Paulo Bydlowski.

Descritores: 1.Mucosite 2.Estomatite 3.Transplante de células-tronco 4.Transplante autólogo 5.Células-tronco hematopoéticas 6.Quimioterapia 


\section{DEDICATÓRIA}

À Priscila, minha esposa, com amor, admiração, carinho e gratidão por sua compreensão e paciência durante a elaboração deste trabalho.

A minha filha Catharyna, com amor, carinho e por você fazer os momentos felizes em minha vida.

A Waldomir e Erny, meus pais, vocês são parte desta realização.

Aos meus irmãos Raul e Margarete pela torcida.

Aos meus sogros Raul Mazzetto e Maria Teresa Mazzetto pelo apoio constante.

Ao Prof. Dr. Fábio Luiz Coracin, seu apoio, incentivo e dedicação desde o início deste trabalho foram fundamentais para a realização e conclusão. 


\section{AGRADECIMENTO ESPECIAL}

Ao Prof. Dr. Sergio Paulo Bydlowski pela postura ética e acolhedora de como deve ser um chefe de serviço. 


\section{AGRADECIMENTOS}

Ao Prof. Dr. Paulo Sergio Silva Santos pela amizade, apoio e incentivo para a realização deste trabalho.

Ao Prof. Dr. Frederico Luiz Dulley pela confiança e aceite inicial deste trabalho.

Aos meus companheiros da Equipe de Odontologia Hospitalar no Hospital Samaritano de São Paulo, Prof. Dr, Frederico Buhatem e Prof. Dra. Karin Sá Fernandes pelo apoio e suporte nos momentos que precisei.

Ao Dr José Tinoco Endrigo Araujo, ao Dr. Vergilio Antonio Rensi Colturato e ao Dr Mair Pedro de Souza pela confiança e compartilhamento de dados compilados no Hospital Amaral Carvalho - Jaú na Unidade de Transplante de Medula.

Aos meus cunhados(as), Thaisi, André, Daniel, Marcia, Willian e aos amigos Miguele e Hamilton pela torcida.

As minhas funcionárias Nívia e Carmeci pelo suporte e paciência comigo durante a realização deste trabalho.

A equipe de Hematologia/TMO do Hospital das Clínicas de São Paulo pela confiança e compartilhamento dos dados compilados em seu departamento.

Ao Programa de Pós Graduação em Ciências Médicas da Faculdade de Medicina da Universidade de São Paulo.

A todos os amigos que me apoiaram para a conclusão deste trabalho. 
"Treine enquanto eles dormem. Estude enquanto eles se divertem. Persista, enquanto eles descansam. E então, vívaro que eles sonham!"

Ninjutsu. 
Esta dissertação ou tese está de acordo com as seguintes normas, em vigor no momento desta publicação:

Referências: adaptado de International Committee of Medical Journals Editors (Vancouver).

Universidade de São Paulo. Faculdade de Medicina. Divisão de Biblioteca e Documentação. Guia de apresentação de dissertações, teses e monografias. Elaborado por Anneliese Carneiro da Cunha, Maria Julia de A. L. Freddi, Maria F. Crestana, Marinalva de Souza Aragão, Suely Campos Cardoso, Valéria Vilhena. 3a ed. São Paulo: Divisão de Biblioteca e Documentação; 2011.

Abreviaturas dos títulos dos periódicos de acordo com List of Journals Indexed in Index Medicus. 


\section{SUMÁRIO}

INTRODUÇÃ̃

OBJETIVOS

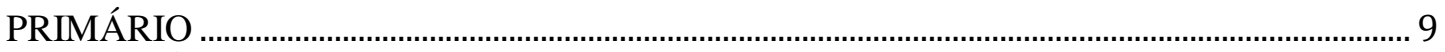

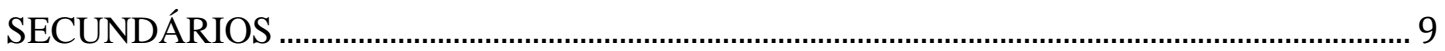

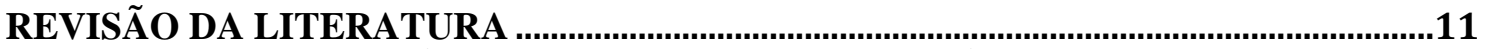

TRANSPLANTE DE CÉLULAS TRONCO HEMATOPOIÉTICAS ………….........................11

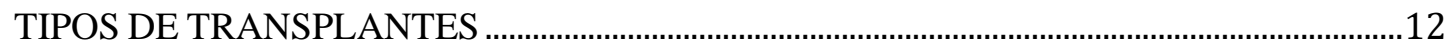

INDICAÇÕES DE TRANSPLANTE ...........................................................................................13

REGIME DE CONDICIONAMENTO ……………..................................................................15

TOXICIDADES DO TRANSPLANTE DE CÉLULAS TRONCO HEMATOPOIÉTICAS ..15

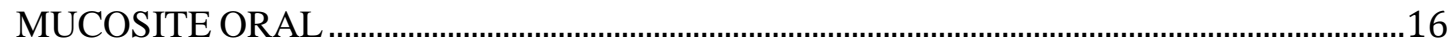

PACIENTES E MÉTODOS .....................................................................................21

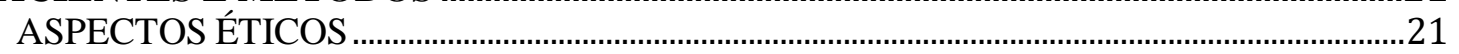

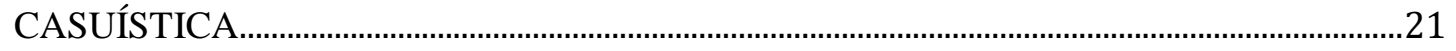

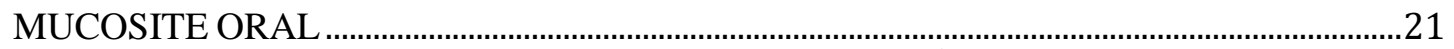

REGIME DE CONDICIONAMENTO E INFUSÃO DAS CÉLULAS TRONCO

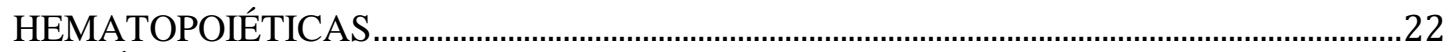

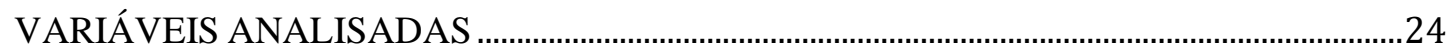

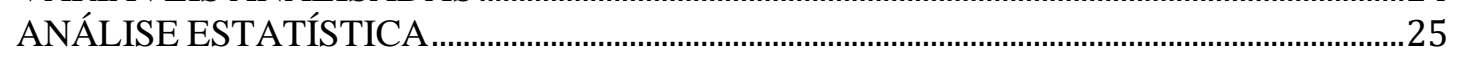

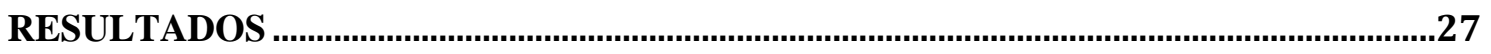

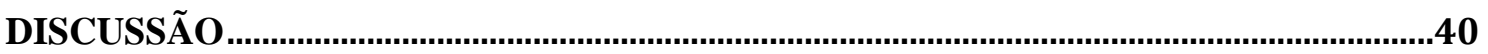

CONCLUSÃO

ANEXO

REFERÊNCIAS BIBLIOGRÁFICAS .......................................................................50 


\section{LISTA DE TABELAS}

Tabela 1: Tipos de transplantes de células-tronco hematopoiéticas............................... 12

Tabela 2: Indicações do transplante de células-tronco hematopoiéticas. ........................ 14

Tabela 3: Escala de Graduação Clínica da Mucosite Oral (Organização Mundial de

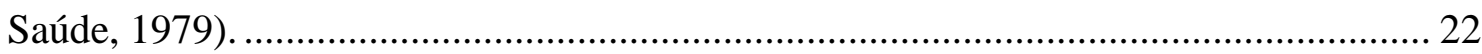

Tabela 4: Número absoluto e porcentagem do sexo dos pacientes analisados............... 27

Tabela 5: Doença de base: dados gerais e divisão de acordo com o sexo...................... 29

Tabela 6: Regime de condicionamento: dados gerais e divisão de acordo com o sexo. 30

Tabela 7: Incidência da mucosite oral (MO) global e de acordo com o sexo................. 31

Tabela 8: Incidência da mucosite oral de acordo com os regimes de condicionamento. 33

Tabela 9: Incidência da mucosite oral relacionada com a doença de base. 38

\section{LISTA DE FIGURAS}

Figura 1: Frequência de mucosite oral por regime de condicionamento........................ 34

Figura 2: Frequência de mucosite oral por regime de condicionamento........................ 34

Figura 3: Frequência de mucosite oral por regime de condicionamento, excluindo

BU/MEL e MEL

Figura 4: Frequência de mucosite oral por regime de condicionamento BU/MEL e

MEL

Figura 5: Frequência de mucosite oral relacionada com doença de base. 38 


\section{LISTA DE ABREVIATURAS}

(D-) - Dias que antecedem o transplante de medula;

(D+) - Dias que sucedem o transplante de medula;

BEAM - Carmustina/Etoposide/Citarabina/Melfalano;

BU - Bussulfano;

Cappesq - Comissão de Ética para Análise de Projetos de Pesquisa;

CIBMTR - Center for International Blood and Marrow Transplant Research

CTH - Células-tronco hematopoiéticas;

DH - Doença de Hodgkin;

DNA - Ácido desoxirribonucleico;

EUA - Estados Unidos da América;

$\mathrm{G}-\mathrm{Grau}$

G-CSF - Fatores de estimulação de colônia de granulócitos;

HLA - Antígenos leucocitários humanos;

ICE - Ifosfamida/Carboplatina/Etoposide;

IL-1 - interleucina-1;

IL-6 - interleucina-6;

LLA - Leucemia linfóide aguda;

LMA - Leucemia mieloide aguda;

LNH - Linfoma de Hodgkin;

MEL Melfalano;

MM - Mieloma múltiplo;

MO - Mucosite oral; 
NF-кB - Fator nuclear kappa B;

OMS - Organização Mundial de Saúde;

TCG - Tumor de células gigantes;

TCTH - Transplante de células-tronco hematopoiéticas;

TNF- $\alpha$ - Fator de necrose tumoral- $\alpha$;

USP - Universidade de São Paulo;

WHO - World Health Organization; 


\section{RESUMO}

Mello WR. Análise dos fatores que influenciam o desenvolvimento da mucosite oral em transplante de células-tronco hematopoiéticas autólogo [Dissertação].

São Paulo: Faculdade de Medicina, Universidade de São Paulo; 2016.

A mucosite é um efeito grave e dose-limitante do tratamento antineoplásico, cujas lesões ulceradas apresentam grande impacto na morbidade e mortalidade dos pacientes, por apresentar dor, restrição alimentar e servindo como porta de entrada para infecções originadas da mucosa bucal, com incidência variável de acordo com a doença de base, idade, condição de saúde bucal, dose e frequência da quimioterapia. A ocorrência de mucosite oral é frequente nos pacientes que receberam altas doses de quimioterapia seguidas de transplante autólogo de células tronco hematopoiéticas. O objetivo deste estudo foi analisar os fatores que influenciam o desenvolvimento da mucosite oral. Foi realizada uma análise retrospectiva em 413 prontuários de pacientes consecutivos submetidos ao transplante autólogo de células tronco hematopoiéticas e os dados coletados incluíram dados demográficos (sexo, idade, doença de base), dados do TCTH (tipo de transplante, regime de condicionamento) e incidência de mucosite oral. Os resultados deste estudo mostraram que a incidência de mucosite foi maior em pacientes do sexo masculino e nos pacientes do sexo feminino com idade média de 29 anos, nos pacientes submetidos ao regime de condicionamento BU/MEL e naqueles pacientes portadores de LMA. Os resultados deste estudo permitiram concluir que a incidência de mucosite oral na casuística analisada foi maior nos pacientes do sexo masculino; nas mulheres jovens quando analisados sexo e idade separadamente, nos pacientes portadores de LMA e naqueles submetidos ao regime de condicionamento BU/MEL.

Descritores: mucosite; estomatite; transplante de células-tronco; transplante autólogo; células-tronco hematopoéticas; quimioterapia. 


\section{ABSTRACT \\ Mello WR. Analysis of factors that influence the oral mucositis development in autologous stem cell transplantation [Dissertation]. São Paulo: "Faculdade de Medicina, Universidade de São Paulo"; 2016.}

Oral mucositis remains as a serious and dose-limiting side-effect of antineoplastic treatment and ulcerated lesions lead to a great impact on morbidity and mortality of patients due to pain, food restriction and serving as a gateway to originate infections of the oral mucosa patients. The incidence of oral mucositis remains uncertain and it is variable according to the underlying disease, age, oral health condition, dose and frequency of chemotherapy. The incidence of oral mucositis is high in patients receiving high-dose chemotherapy followed by autologous transplantation of hematopoietic stem cells. The aim of this study was to analyze the factors that influence the development of oral mucositis. a retrospective analysis of 413 medical records of consecutive patients undergoing autologous hematopoietic stem cell transplantation. Data collected included demographic data was performed (sex, age, underlying disease), HSCT data (type of transplant conditioning regimen) and incidence oral mucositis. The results of this study showed that the incidence of mucositis was higher in male patients and female patients with a mean age of 29 years, in patients undergoing conditioning regimen comprises BU / MEL and in those patients with AML. The results of this study showed that the incidence of oral mucositis in the analyzed sample was higher in males; in young women when analyzed separately sex and age, in patients with AML and those submitted to the BU / MEL conditioning regimen.

Descriptors: mucositis; stomatitis; stem cell transplantation; transplantation, autologous; hematopoietic stem cells; drug therapy. 
INTRODUÇÃO 


\section{INTRODUÇÃO}

O transplante de células-tronco hematopoiéticas (TCTH) é o tipo de tratamento de escolha para doenças que afetam a produção das células da medula óssea e elementos do sistema imunológico, baseado na coleta de medula óssea, células do sangue de cordão umbilical ou células mobilizadas a partir do sangue periférico. Somente em março de 1969 que o grupo de Seattle (EUA), o Dr. Donnal Thomas realizou o primeiro TCTH alogênico com sucesso em paciente portador de leucemia mieloide aguda, utilizando altas doses de irradiação corporal total seguida da infusão de medula óssea HLA idêntico aparentado.

Os avanços nas técnicas de transplante e estratégias de cuidados de suporte resultaram em uma melhora significativa na sobrevida: $70-80 \%$ das pessoas que sobrevivem aos primeiros 2 anos após o transplante apresentam, a longo prazo, maiores chances de cura.

O TCTH tem sido utilizado há mais de 30 anos quando há doenças hematológicas malignas, como mieloma, linfomas, leucemias, anemias aplásicas e síndrome mielodisplásicas, com altos índices de sucesso. Recentemente, este procedimento tem sido adotado como uma forma de imunossupressão em altas doses em pacientes selecionados com doenças auto-imunes, que são resistentes às terapias convencionais.

Os TCTH são classificados de acordo com a relação paciente-doador e a origem anatômica das células-tronco. No TCTH alogênico, a fonte de células é a medula óssea ou as células periféricas coletadas por aférese de um doador, aparentado ou não aparentado. Os doadores aparentados, como os não aparentados, devem apresentar compatibilidade aos antígenos leucocitários humanos (HLA) do receptor, estar em boas 
condições de saúde, pois diferente do que costuma acontecer nos transplantes de órgãos sólidos, o nível de compatibilidade imunológica entre doador e receptor é essencial para o sucesso no TCTH. O segundo tipo é o TCTH autólogo onde a fonte das célulastronco hematopoiéticas $(\mathrm{CTH})$ é o próprio paciente, seja por medula óssea ou periférica coletadas por aférese, tendo como proposta terapêutica a reconstrução da hematopoiese e prevenir as citopenias prolongadas. A terapia mieloablativa com altas doses seguida pela infusão das células-tronco hematopoiéticas do própio paciente apresenta grandes chances de cura para os casos de leucemia linfóide aguda (LLA), em alguns tumores pediátricos, como tratamento de primeira linha nos casos de mieloma múltiplo (MM) em pacientes com idade e co-morbidade elegível. O TCTH autólogo é utilizado também como terapia padrão nos casos de recaída de Doença de Hodgkin (DH) quimiossenssível e nos casos de linfomas não-Hodgkin (LNH) intermediários de alto risco.

O terceiro tipo é o TCTH singênico onde o doador é um irmão gêmeo idêntico e o quarto tipo é o TCTH de cordão umbilical onde as células progenitoras são coletadas de cordão umbilical criopreservadas.

O TCTH está indicado para os tratamentos das doenças hematológicas, oncológicas, imunológicas e hereditárias, dependendo, em geral, da fase da doença em que o paciente se encontra. A realização do TCTH ocorre a partir da coleta, por aspiração, das células tronco hematopoiéticas, que pode ser da própria medula óssea, do sangue periférico ou do cordão umbilical.

Entende-se como regime de condicionamento pré TCTH o conjunto de drogas quimioterápicas utilizado em altas doses, associado ou não à radioterapia corporal total, aplicado no paciente dias antes de ser infundida a medula óssea ou as células tronco periféricas. Tal procedimento objetiva o estabelecimento de um grau de 
imunossupressão necessário para que o enxerto não seja reconhecido como um corpo estranho e destruído pelas células imunocompetentes do receptor, eliminar um número máximo de células neoplásicas residuais do receptor, e gerar, dessa forma, um "espaço" onde a nova medula possa proliferar.

A escolha do quimioterápico baseia-se em função do tipo de doença, condição clínica, idade do paciente e o seu histórico de tratamento prévio. As principais drogas utilizadas nos regimes de condicionamento são o bussulfano, ciclofosfamida, melfalano, arabinosídeo C, carmustina, fludarabina, carboplatina e vepeside. Quando associado à radioterapia, normalmente utiliza-se a irradiação corporal total em doses que podem variar de 300 a $1.200 \mathrm{cGy}$.

As toxicidades gastrointestinal e hepática são causas de morbidade durante e após o transplante de células tronco hematopoiéticas. O regime de condicionamento com altas doses de quimioterapia para o TCTH acarreta nos pacientes efeitos adversos relacionados com quimioterapia durante o período inicial e após o transplante com tempo médio de duração de 15 dias após a infusão das células tronco hematopoiéticas.

A quebra da barreira mucosa do trato digestório é definida como mucosite, presente desde a mucosa oral até o ânus. Esta é uma complicação comum durante o período póstransplante imediato e acomete aproximadamente $80 \%$ dos receptores de transplante. Dentre as principais drogas capazes de induzir a toxicidade gastrointestinal, são citados o busulfan, o etoposídeo, o melfalano e o metotrexato. Outra forma de toxicidade inclui a diarreia, que pode estar presente em aproximadamente metade dos pacientes que receberam altas doses de quimioterapia e radioterapia como parte do regime de condicionamento e ocorre por volta de 2 semanas após o transplante. Os principais agentes alquilantes, o bussulfano e combinação regimes são etiologias que podem levar à diarreia devido à inflamação da mucosa. 
A mucosite é um efeito grave e dose-limitante do tratamento antineoplásico, cujas lesões ulceradas apresentam grande impacto na morbidade dos pacientes, por apresentar dor, restrição alimentar e servindo como porta de entrada para infecções originadas da mucosa bucal, cuja incidência é variável de acordo com a doença de base, idade, condição de saúde bucal dose e frequência da quimioterapia. A primeira descrição detalhada dos processos biológicos do desenvolvimento da mucosite fala que cada uma das fases descritas é independente entre si e se apresenta como consequência de uma rede de ações mediadas por citocinas inflamatórias associada com o dano ao epitélio pelo agente quimioterápico e/ou radioterápico, sendo influenciadas pela presença da flora bacteriana bucal e a neutropenia. Atualmente a mucosite é descrita como um processo complexo caracterizado pela ocorrência de 5 fases compreendendo eventos não apenas epiteliais, mas relacionados a outros tecidos envolvidos pela toxicidade do tratamento do câncer. A fase de iniciação da mucosite acontece pela liberação de íons reativos de oxigênio no tecido envolvido em resposta à quimioterapia e/ou radioterapia, causando exposição do tecido a estes agentes tóxicos levando ao dano direto às células, tecidos e vasos sanguíneos. Estes íons reativos de oxigênio podem estimular um número grande de fatores de transcrição que caracterizam a resposta do tecido aos agentes citotóxicos. A próxima fase, de super-regulação com geração de mensageiros celulares, é resultado de vários eventos acontecendo juntos culminando na morte celular programada após o dano do DNA pelos íons reativos de oxigênio gerados na fase de iniciação. Esta morte celular não é suficiente para desencadear as lesões de mucosite comumente vistas, sendo que concomitantemente a isto, a liberação de fatores,

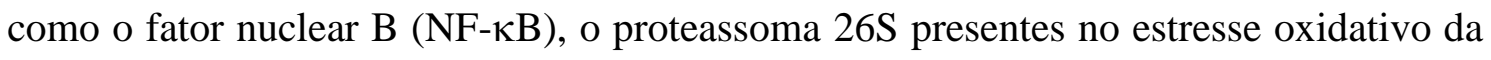
mucosa, via da esfingomielinase e cadeia das caspases podem super-regular o processo. $\mathrm{Na}$ fase de sinalização e amplificação as citocinas inflamatórias liberadas durante a 
quimioterapia e/ou radioterapia atuam amplificando a lesão na mucosa previamente iniciada. A ativação das cadeias esfingomielinase e caspase pelos mensageiros leva à liberação de fator de necrose tumoral- $\alpha$ (TNF- $\alpha$ ), interleucina-1 (IL-1) e interleucina-6 (IL-6). Estas citocinas são mediadoras da lesão tecidual secundária ao TNF- $\alpha$. A consequência desta fase culmina com um tecido biologicamente alterado, porém com aparência clínica normal. Na fase de ulceração a colonização bacteriana por grampositivos, gram-negativos e anaeróbios podem levar à bacteremia e sepses. Os produtos da parede celular bacteriana podem ativar os macrófagos teciduais levando à liberação de maior quantidade de fatores pró-inflamatórios (TNF- $\alpha$, IL-1, IL-6), amplificando e acelerando os danos teciduais. Por fim, com a recuperação dos neutrófilos, a renovação celular começa a reestabelecer. Há a interação de sinalizadores da matriz extracelular. Após a cicatrização a mucosa ficará aparentemente normal, porém o microambiente continua alterado significativamente com indícios de angiogênese residual.

Atualmente, sabe-se que todos os tecidos envolvidos no processo da mucosite podem apresentar modificações genéticas ou serem resistentes à toxicidade relacionada ao tratamento. Esta hipótese pode ser evidenciada de acordo com as diferenças individuais na susceptibilidade à quimioterapia e/ou radioterapia (Dörr, 2002), polimorfismos de genes relacionados com o metabolismo das drogas utilizadas (por exemplo o metotrexato, melfalan) (Kühne, 2008).

As taxas de incidência da mucosite oral grau 3 e 4 variam de $5 \%$ a $15 \%$ e possuem resultados significativos em virtude dos resultados clínicos (modificação do esquema terapêutico) e econômicos (aumento nos dias de internação, utilização de analgésicos opióides, nutrição parenteral total) (Sonis, 2001). A associação entre a mucosite e a infecção foi observada por RUESCHER ET AL (1998), que detectou que 
as bacteremias mais comuns em pacientes submetidos ao transplante de medula óssea foram de origem estreptocócica (Ruescher, 1998). 
OBJETIVOS 


\section{OBJETIVOS}

\section{PRIMÁRIO}

- Avaliar a incidência da mucosite oral em uma coorte retrospectiva de pacientes submetidos ao transplante de células tronco hematopoiéticas autólogo.

\section{SECUNDÁRIOS}

- Avaliar os fatores relacionados ao desenvolvimento da mucosite oral nos pacientes submetidos ao transplante autólogo de células tronco hematopoiéticas:

- Idade, sexo do paciente, regime de condicionamento, doença de base. 
REVISÃO DA LITERATURA 


\section{REVISÃO DA LITERATURA}

\section{TRANSPLANTE DE CÉLULAS TRONCO HEMATOPOIÉTICAS}

O transplante de células-tronco hematopoiéticas (TCTH) é o tipo de tratamento de escolha para doenças que afetam a produção das células da medula óssea e elementos do sistema imunológico, baseado na coleta de medula óssea, células do sangue de cordão umbilical ou células mobilizadas a partir do sangue periférico (Li,2012). Este tratamento é resultado de mais de um século de pesquisas intensas, inicialmente em nível laboratorial seguido de pesquisas em cães e posteriormente em humanos. Porém somente em março de 1969, que o grupo de Seattle (EUA), o Dr. Donnal Thomas realizou o primeiro TCTH alogênico com sucesso em paciente portador de leucemia mieloide aguda, utilizando altas doses de irradiação corporal total seguida da infusão de medula óssea HLA idêntico aparentado (Thomas, 1975; Santos, 1983).

Os avanços nas técnicas de transplante e estratégias de cuidados de suporte resultaram em uma melhora significativa na sobrevida: $70-80 \%$ das pessoas que sobrevivem aos primeiros 2 anos após o transplante apresentam, a longo prazo, maiores chances de cura (Socié, 1999; Bathia, 2007).

O TCTH tem sido utilizado por mais de 30 anos para doenças hematológicas malignas, como o mieloma, linfomas, leucemias, anemias aplásicas e síndrome mielodisplásicas, com altos índices de sucesso (Durey, 2009; Rebeiro, 2016). Recentemente, este procedimento tem sido adotado como uma forma de imunossupressão em altas doses em pacientes selecionados com doenças auto-imunes que são resistentes às terapias convencionais (Rebeiro, 2016). 


\section{TIPOS DE TRANSPLANTES}

Os TCTH são classificados de acordo com a relação paciente-doador, e a origem anatômica das células-tronco (Amos, 1995). A Tabela 1 esquematiza as principais formas de Transplante de Células-Tronco Hematopoiéticas.

Tabela 1: Tipos de transplantes de células-tronco hematopoiéticas.

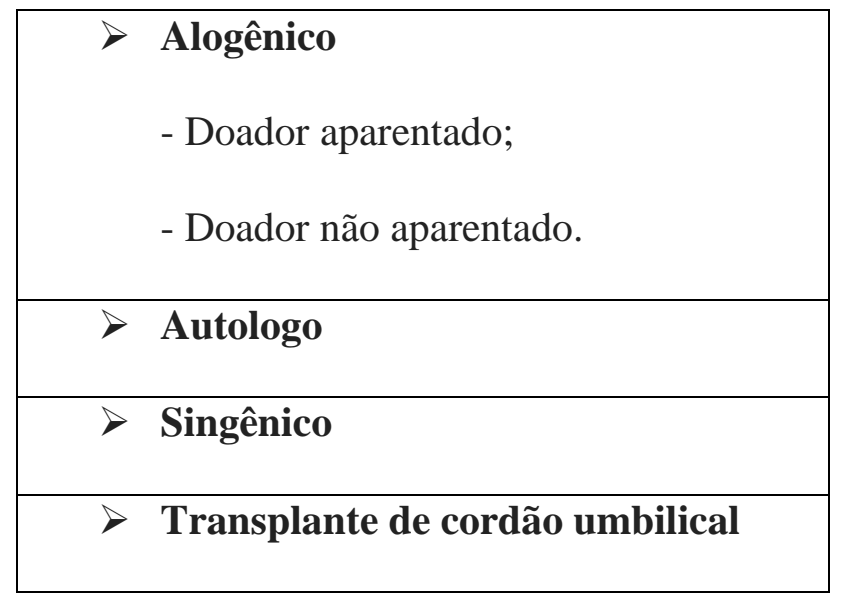

No TCTH alogênico a fonte de células é a medula óssea ou as células periféricas coletadas por aférese de um doador aparentado ou de um doador não aparentado. Tanto os doadores aparentados como os não aparentados, devem apresentar compatibilidade aos antígenos leucocitários humanos (HLA) do receptor, estar em boas condições de saúde, pois diferente do que costuma acontecer nos transplantes de órgãos sólidos, o nível de compatibilidade imunológica entre doador e receptor é essencial para o sucesso no TCTH (Thomas, 1975).

O segundo tipo é o TCTH autólogo onde a fonte das células-tronco hematopoiéticas $(\mathrm{CTH})$ é o próprio paciente, seja por medula óssea ou periférica coletadas por aférese, tendo como proposta terapêutica a reconstrução da hematopoiese e prevenir as citopenias prolongadas (Rosenbeck, 2010). A terapia mieloablativa com altas doses seguida pela infusão das células-tronco hematopoiéticas do própio paciente 
apresenta grandes chances de cura para os casos de leucemia linfóide aguda (LLA) (Bueno, 2011), em alguns tumores pediátricos (Westermann, 1999), como tratamento de primeira linha nos casos de mieloma múltiplo (MM) em pacientes com idade e comorbidade elegível (Bonassa, 2012). O TCTH autólogo é utilizado também como terapia padrão nos casos de recaída de Doença de Hodgkin (DH) quimiossenssível e nos casos de linfomas não-Hodgkin (LNH) intermediários de alto risco (Jones, 2008; Bonassa, 2012).

O terceiro tipo é o TCTH singênico onde o doador é um irmão gêmeo identico e o quarto tipo é o TCTH de cordão umbilical onde as células progenitoras são coletadas de cordão umbilical criopreservadas (Amos, 1995).

\section{INDICAÇÕES DE TRANSPLANTE}

O TCTH está indicado para os tratamentos das doenças hematológicas, oncológicas, imunológicas e hereditárias dependendo, em geral, da fase da doença em que o paciente se encontra (Wingard, 1987). A Tabela 2 ilustra as principais indicações do TCTH.

A realização do TCTH ocorre a partir da coleta por aspiração das células tronco hematopoiéticas que pode ser da própria medula óssea, por sangue periférico ou cordão umbilical (Neitzert, 1998).

Na coleta por aspiração da medula são feitas diversas punções nas cristas ilíacas posteriores com agulhas especiais para este procedimento. A quantidade necessária para o transplante é calculada em média de 10 a $15 \mathrm{ml} / \mathrm{kg}$ de peso do receptor (Thomas, 1970). 
A coleta das células tronco hematopoiéticas ocorre com o auxílio de uma máquina de aférese após a mobilização da medula óssea para o sangue periférico, utilizando fatores de estimulação de colônia de granulócitos (G-CSF) e, nos casos de TCTH autólogo, pode haver a inclusão de quimioterapia prévia (Anderlini, 1999).

E na coleta do cordão umbilical o procedimento e feito logo após o nascimento da criança, processado posteriormente e criopreservado até a infusão. Sua indicação se mostra de forma limitada em função do número de células ser baixo (Anderlini, 1999).

Tabela 2: Indicações do transplante de células-tronco hematopoiéticas.

\begin{tabular}{|l|l|}
\hline Doenças onco-hematológicas \\
- Leucemia linfóide aguda \\
- Leucemia mieloide crônica \\
- Síndromes mielodisplásicas \\
- Linfoma não-Hodgkin \\
- Linfoma de Hodgkin \\
- Mieloma múltiplo \\
- Mieloesclerose aguda maligna \\
\hline Doenças hematológicas \\
- Anemia aplástica grave \\
- Anemia de Fanconi \\
- Aplasia pura da série vermelha \\
- Hemoglobinúria paroxística noturna \\
- Hemoglobinopatias \\
Acidentes de radiação \\
\hline Doenças Oncológicas \\
- Tumor de testículo \\
- Tumor de mama \\
- Tumor de ovário \\
- Neuroblastoma \\
- Sarcoma de Ewing \\
- Tumor de sistema nervoso central \\
- Outros tumores \\
\hline Doenças não-neoplásicas \\
- Imunodeficiência grave combinada \\
- Síndrome de Wiskott-Aldrich \\
- Esclerose múltipla \\
- Lúpus eritematoso sistêmico grave progressivo \\
- Artrite reumatoide grave progressiva \\
- Osteopetrose \\
- Adrenoleucodistrofia \\
- Mucopolissacaridose \\
- Doença de Gaucher \\
- Outras \\
\hline
\end{tabular}




\section{REGIME DE CONDICIONAMENTO}

Entende-se como regime de condicionamento pré TCTH o conjunto de drogas quimioterápicas utilizado em altas doses, associado ou não à radioterapia corporal total, aplicado no paciente dias antes de ser infundida a medula óssea ou as células tronco periféricas. Tal procedimento objetiva o estabelecimento de um grau de imunossupressão necessário para que o enxerto não seja reconhecido como um corpo estranho e destruído pelas células imunocompetentes do receptor, eliminar um número máximo de células neoplásicas residuais do receptor, e gerar, dessa forma, um "espaço" onde a nova medula possa proliferar (Hickman, 1979; Storb,1994)

A escolha do quimioterápico baseia-se em função do tipo de doença, condição clínica, idade do paciente e o seu histórico de tratamento prévio. As principais drogas utilizadas nos regimes de condicionamento são o bussulfano, ciclofosfamida, melfalano, arabinosídeo C, carmustina, fludarabina, carboplatina, vepeside. Quando associado a radioterapia, normalmente utiliza-se a irradiação corporal total em doses que podem variar de 300 a 1.200cGy (Hickman, 1979).

\section{TOXICIDADES DO TRANSPLANTE DE CÉLULAS TRONCO HEMATOPOIÉTICAS}

As toxicidades gastrointestinal e hepática são causas de morbidade durante e após o transplante de células tronco hematopoiéticas. O regime de condicionamento com altas doses de quimioterapia para o TCTH acarreta nos pacientes efeitos adversos relacionados com quimioterapia durante o período inicial e após o transplante com 
tempo médio de duração de 15 dias após a infusão das células tronco hematopoiéticas (Weisdorf, 1990).

A quebra da barreira mucosa do trato digestório é definida como mucosite, presente desde a mucosa oral até o ânus. Esta é uma complicação comum durante o período pós-transplante imediato e acomete aproximadamente $80 \%$ dos receptores de transplante. Dentre as principais drogas capazes de induzir a toxicidade gastrointestinal são citados o bussulfano, o etoposídeo, o melfalano e o metotrexato (Vera-Llonch, 2007; Santos, 2011; Coracin, 2013).

Outra forma de toxicidade inclui a diarreia que pode estar presente em aproximadamente metade dos pacientes que receberam altas doses de quimioterapia e radioterapia como parte do regime de condicionamento e ocorre por volta de 2 semanas após o transplante. Os principais agentes alquilantes, o bussulfano e combinação regimes são etiologias que podem levar à diarreia devido à inflamação da mucosa (Cox, 1994).

\section{MUCOSITE ORAL}

A mucosite é um efeito grave e dose-limitante do tratamento antineoplásico, cujas lesões ulceradas apresentam grande impacto na morbidade dos pacientes, por apresentar dor, restrição alimentar e servindo como porta de entrada para infecções originadas da mucosa bucal, cuja incidência é variável de acordo com a doença de base, idade, condição de saúde bucal dose e frequência da quimioterapia (Sonis, 1991; Sonis, 1998;

Sonis, 2004). A primeira descrição detalhada dos processos biológicos do desenvolvimento da mucosite foi feito por Sonis (1998) onde cada uma das fases descritas é independente entre si e se apresenta como consequência de uma rede de 
ações mediadas por citocinas inflamatórias associada com o dano ao epitélio pelo agente quimioterápico e/ou radioterapia, sendo influenciadas pela presença da flora bacteriana bucal e a neutropenia (Sonis, 1998). As fases incluem:

1. Fase inflamatória ou de reação vascular ocorre como reação inicial à exposição aos agentes quimioterápicos, sendo amplificada quando há associação da radioterapia. Nesta fase ocorre a liberação de citocinas inflamatórias, como a interleucina 1 e o fator de necrose tumoral, com exacerbação da resposta tecidual;

2. A fase epitelial acontece como resposta não seletiva do epitélio às drogas utilizadas no tratamento do câncer. As células em divisão são afetadas da mesma maneira que as células tumorais, culminando com a redução na renovação celular. Esta fase está profundamente relacionada com a produção de lesões ulceradas, decorrente da atrofia epitelial secundária à renovação celular reduzida;

3. A fase ulcerativa é uma consequência da atrofia epitelial e facilitada pelo atrito e pelos microtraumas à mucosa oral.

4. A última fase culmina com a cicatrização das lesões e está diretamente relacionada com a renovação celular que volta a ocorrer, voltando à divisão e diferenciação celular.

Atualmente a mucosite é descrita como um processo complexo caracterizado pela ocorrência de 5 fases compreendendo eventos não apenas epiteliais, mas relacionados a outros tecidos envolvidos pela toxicidade do tratamento do câncer (Sonis, 2004). A fase de iniciação da mucosite acontece pela liberação de íons reativos de oxigênio no tecido envolvido em resposta à quimioterapia e/ou radioterapia, causando exposição do tecido 
a estes agentes tóxicos levando ao dano direto às células, tecidos e vasos sanguíneos (Gaté, 1999). Estes íons reativos de oxigênio podem estimular um número grande de fatores de transcrição que caracterizam a resposta do tecido aos agentes citotóxicos (Culy, 2001). A próxima fase, de super-regulação com geração de mensageiros celulares, é resultado de vários eventos acontecendo juntos culminando na morte celular programada após o dano do DNA pelos íons reativos de oxigênio gerados na fase de iniciação. Esta morte celular não é suficiente para desencadear as lesões de mucosite comumente vistas, sendo que concomitante a isto a liberação de fatores, como o fator

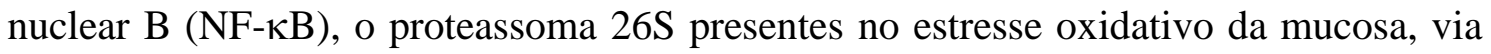
da esfingomielinase e cadeia das caspases podem super-regular o processo (Maddens, 2002). Na fase de sinalização e amplificação as citocinas inflamatórias liberadas durante a quimioterapia e/ou radioterapia atuam amplificando a lesão na mucosa previamente iniciada. A ativação das cadeias esfingomielinase e caspase pelos mensageiros leva à liberação de fator de necrose tumoral- $\alpha$ (TNF- $\alpha$ ), interleucina-1 (IL-1) e interleucina-6 (IL-6). Estas citocinas são mediadoras da lesão tecidual secundária ao TNF- $\alpha$. A consequência desta fase culmina com um tecido biologicamente alterado, porém com aparência clínica normal. Na fase de ulceração, a colonização bacteriana por grampositivos, gram-negativos e anaeróbios podem levar à bacteremia e sepses. Os produtos da parede celular bacteriana podem ativar os macrófagos teciduais levando à liberação de maior quantidade de fatores pró-inflamatórios (TNF- $\alpha$, IL-1, IL-6), amplificando e acelerando os danos teciduais. Por fim, com a recuperação dos neutrófilos, a renovação celular começa a reestabelecer. Há a interação de sinalizadores da matriz extracelular. Após a cicatrização a mucosa ficará aparentemente normal, porém o microambiente continua alterado significantemente com indícios de angiogênese residual (Sonis, 2004). 
Atualmente, sabe-se que todos os tecidos envolvidos no processo da mucosite podem apresentar modificações genéticas ou serem resistentes à toxicidade relacionada ao tratamento. Esta hipótese pode ser evidenciada de acordo com as diferenças individuais na susceptibilidade à quimioterapia e/ou radioterapia (Dörr, 2002), polimorfismos de genes relacionados com o metabolismo das drogas utilizadas (por exemplo o metotrexato, melfalan) (Kühne, 2008).

As taxas de incidência da mucosite oral grau 3 e 4 variam de $5 \%$ a $15 \%$ e possuem resultados significantes em virtude dos resultados clínicos (modificação do esquema terapêutico) e econômicos (aumento nos dias de internação, utilização de analgésicos opióides, nutrição parenteral total) (Sonis, 2001). A associação entre a mucosite e infecção foi observada por RUESCHER ET AL (1998), que detectou que as bacteremias mais comuns em pacientes submetidos ao transplante de medula óssea foram de origem estreptocócica (Ruescher, 1998). 


\section{PACIENTES E MÉTODOS}




\section{PACIENTES E MÉTODOS}

\section{ASPECTOS ÉTICOS}

Este estudo foi submetido e aprovado pela Comissão de Ética para Análise de Projetos de Pesquisa do Hospital das Clínicas da Faculdade de Medicina da USP (Cappesq $\left.-\mathrm{n}^{\circ} 835.813\right)$.

\section{CASUÍSTICA}

Foram analisados neste estudo retrospectivo os dados de prontuários de pacientes submetidos ao transplante autólogo de células tronco hematopoiéticas no Hospital das Clínicas da Faculdade de Medicina da USP e no Hospital Amaral Carvalho de Jaú no período entre 2008 e 2012 e os dados coletados incluíram:

1. Dados Demográficos: idade e sexo do paciente, doença de base;

2. Dados referentes ao transplante: regime de condicionamento com alta dose de quimioterapia;

3. Dados referentes à mucosite oral: graduação clínica baseada nos critérios da Organização Mundial de Saúde (OMS).

\section{MUCOSITE ORAL}

Todos os prontuários de pacientes continham as avaliações diárias da mucosite oral durante o período do TCTH autólogo. Os critérios para graduação clínica da 
mucosite oral incluíram a presença de eritema até a formação de ulcerações que viessem a comprometer as funções de mastigação e deglutição. A graduação da mucosite foi realizada utilizando os critérios da Escala de Graduação da Mucosite Oral da Organização Mundial da Saúde (OMS) (World Health Organization WHO, 1979), conforme Tabela 3.

Tabela 3: Escala de Graduação Clínica da Mucosite Oral (Organização Mundial de Saúde, 1979).

\begin{tabular}{|l|l|}
\cline { 2 - 2 } \multicolumn{1}{l|}{} & Manifestação clínica \\
\hline Grau 0 & Sem alteração. \\
\hline Grau 1 & Eritema, irritação, dor. \\
\hline Grau 2 & Eritema, úlcera, pode alimentar-se com sólido. \\
\hline Grau 3 & Úlceras e requer somente dieta líquida. \\
\hline Grau 4 & Úlcera, impossível a alimentação. \\
\hline
\end{tabular}

Ref.: World Health Organization. Handbook for Reporting Results of Cancer Treatment. Geneva, Switzerland: World Health Organization; 1979. pp. 15-22.

\section{REGIME DE CONDICIONAMENTO E INFUSÃO DAS CÉLULAS TRONCO HEMATOPOIÉTICAS}

Os pacientes receberam o regime de condicionamento, internados, consistindo de altas doses de quimioterapia seguidos pela infusão das células tronco hematopoiéticas autóloga de acordo com o protocolo dos Serviços. A determinação de cada regime de 
condicionamento foi baseada na doença a ser tratada, incluindo:

- Melfalano $200 \mathrm{mg} / \mathrm{m} 2$

- Bussulfano $3 \mathrm{mg} / \mathrm{kg} / \mathrm{dia} / 4$ dias -Melfalano $100 \mathrm{mg} / \mathrm{m}^{2}$

- BEAM 400 (Carmustina $400 \mathrm{mg} / \mathrm{m}^{2}$-Etoposide $400 \mathrm{mg} / \mathrm{m}^{2} / \mathrm{dia} / 4$ dias Citarabina $400 \mathrm{mg} / \mathrm{m}^{2} / \mathrm{dia} / 4$ dias -Melfalano $140 \mathrm{mg} / \mathrm{m}^{2}$ )

- BEAM (Carmustina $300 \mathrm{mg} / \mathrm{m}^{2}$-Etoposide $200 \mathrm{mg} / \mathrm{m}^{2} / \mathrm{dia} / 4$ dias $\mathrm{LH}$ Citarabina $400 \mathrm{mg} / \mathrm{m}^{2} / \mathrm{dia} / 4$ dias LNH -Melfalano $140 \mathrm{mg} / \mathrm{m}^{2}$ )

- Bussulfano $4 \mathrm{mg} / \mathrm{kg} / \mathrm{dia} / 4$ dias -Melfalano $140 \mathrm{mg} / \mathrm{m}^{2}$

- ICE ((Ifosfamida $10 \mathrm{~g} / \mathrm{m} 2$, Carboplatina 1500 mg/m2 e Etoposide 2400 mg/m2)

O TCTH autólogo foi realizado após 24 horas do término do regime de condicionamento. As células tronco hematopoiéticas criopreservadas foram infundidas nos pacientes após descongelamento das bolsas de transferência. As células tronco hematopoiéticas foram infundidas por via intravenosa em uma velocidade média de cinco mililitros por minuto em equipo para componentes sanguíneos e monitorizada rigorosamente pela equipe médica e de enfermagem.

Por convenção, o dia da infusão foi considerado o "dia zero", sendo que os dias que antecederam o transplante foram definidos como "negativos" (D-) e os que sucederam foram denominados como "positivos" (D+).

A aplasia medular caracterizou-se pela diminuição da produção dos elementos sanguíneos da medula óssea, ocasionada pelas quimioterapias utilizadas no regime de condicionamento, confirmada por hemograma. O período de neutropenia foi definido 
quando a contagem de leucócitos totais foi <1000/mm3.

O dia da enxertia medular foi considerado o primeiro de três dias consecutivos com contagem periférica de neutrófilos $\geq 500 / \mathrm{mm}^{3}$ (Weaver, 1997).

\section{VARIÁVEIS ANALISADAS}

Todos os prontuários foram revistos e os dados demográficos, doença de base e graduação da mucosite oral foram coletados. A partir destes dados foi elaborado um banco de dados para análise que incluiu:

1. Sexo do paciente:

a. Masculino vs feminino.

2. Idade do paciente ao transplante:

a. Mediana (máxima - mínima)

3. Doença de base para qual o TCTH autólogo foi indicado;

4. Regime de condicionamento utilizado;

5. Graduação clínica da mucosite oral (MO):

a. Grau 0 vs Graus 1 a 4 . 


\section{ANÁLISE ESTATÍSTICA}

Os resultados foram submetidos à estatística descritiva para caracterizar a amostra, as médias e medianas. O teste não paramétrico de Qui-Quadrado foi utilizado para comparar se as frequências de homens e de mulheres foram as mesmas no que diz respeito a ser ou não portadores de mucosite. O teste não paramétrico de Kruskall Wallis foi aplicado para comparar se houve diferença estatística entre as idades dos pacientes não portadores e portadores de diferentes níveis de mucosite. O teste de múltipla comparação de Dunn foi aplicado para apontar as possíveis diferenças entre os níveis de portadores e não portadores de mucosite. 


\section{RESULTADOS}




\section{RESULTADOS}

Foram inseridos e analisados 413 prontuários de pacientes consecutivos submetidos ao transplante autólogo de células tronco hematopoiéticas nos Centros de Transplante citados na Seção Pacientes e Métodos, no período entre 2008 a 2012. Destes, $229(55,5 \%)$ eram do sexo masculino e $184(44,6 \%)$ do sexo feminino com mediana de idade total de 44 anos $(6-69$ anos). A Tabela 4 apresenta o número absoluto e a porcentagem dos sexos dos pacientes analisados.

Tabela 4: Número absoluto e porcentagem do sexo dos pacientes analisados.

\begin{tabular}{|c|c|c|c|c|}
\hline & $\mathbf{N}$ & $\mathbf{( \% )}$ & Mediana Idade & Variação \\
\hline Homem & 229 & 55,5 & 43,4 & $6-67$ \\
\hline Mulher & 184 & 44,5 & 44,1 & $6-69$ \\
\hline
\end{tabular}

Nota: A mediana de idade da amostra $(n=413)$ foi de 44 anos $(6-69)$.

Os resultados da idade dos pacientes em relação ao desenvolvimento da mucosite oral mostraram não haver diferença estatística entre os escores médios das idades de pacientes que não desenvolveram e desenvolveram qualquer grau de mucosite $(\mathrm{p}=0,37)$. Quando avaliados apenas os pacientes do sexo masculino e a incidência de mucosite oral não houve diferença estatística entre os escores médios das idades dos pacientes que não desenvolveram e desenvolveram mucosite $(\mathrm{p}=0,62)$. Quando avaliados apenas os pacientes do sexo feminino e a incidência de mucosite oral houve diferença estatística entre os escores médios das idades de pacientes que não desenvolveram e desenvolveram grau de mucosite $(\mathrm{p}<0,05)$. O teste de múltipla comparação de Dunn foi aplicado para mostrar as possíveis diferenças entre os níveis de 
pacientes que não desenvolveram e desenvolveram mucosite e mostrou que a mucosite grau 3 apresentou idade média $(29,00)$ menor que os pacientes portadores dos graus 1 $(46,50), 4(54,00)$ e aqueles que não desenvolveram mucosite $(50,50)$.

De acordo com as doenças de base submetidas ao TCTH autólogo, dos 413 prontuários analisados $214(51,81 \%)$ apresentaram mieloma múltiplo (MM), 87 $(21,06 \%)$ apresentaram doença de Hodgkin (DH), 70 (16,94\%) apresentaram linfoma não-Hodgkin (LNH), 22 (5,32\%) apresentaram leucemia mieloide aguda (LMA), 16 $(3,87 \%)$ apresentaram tumor de células germinativas (TCG), $1(0,24 \%)$ apresentou leucemia linfocítica aguda (LLA) e 3 (0,72\%) apresentaram outras doenças (neuroblastoma, amiloidose e tumor desmoplásico de células pequenas). Quanto a doença de base, dos 229 prontuários de pacientes do sexo masculino fizeram parte, 1 caso com leucemia linfóide aguda (LLA), 13 casos com leucemia mieloide aguda (LMA), 12 caso com tumor de célula gigante (TCG), 43 casos com doença de Hodgkin (HD), 118 casos com mieloma múltiplo (MM), 41 casos com linfoma não-Hodgkin (LNH), 1 caso com outros tumores não especificado no prontuário (Outros) e dos 184 prontuários de pacientes do sexo feminino fizeram parte, 9 casos com leucemia mieloide aguda (LMA), 4 casos com tumor de célula gigante (TCG), 44 casos com doença de Hodgkin (DH), 96 casos com mieloma múltiplo (MM), 29 casos com linfoma não-Hodgkin (LNH), 2 casos com outros tumores não especificados no prontuário (Outros). A Tabela 5 apresenta as doenças de base, seus dados gerais e divisão de acordo com o sexo. 
Tabela 5: Doença de base: dados gerais e divisão de acordo com o sexo.

\begin{tabular}{|c|c|c|c|c|c|c|c|}
\cline { 2 - 8 } \multicolumn{1}{c|}{} & LLA & LMA & TCG & HD & MM & LNH & Outros \\
\hline $\mathbf{n = 4 1 3}$ & $\mathbf{1}$ & $\mathbf{2 2}$ & $\mathbf{1 6}$ & $\mathbf{8 7}$ & $\mathbf{2 1 4}$ & $\mathbf{7 0}$ & $\mathbf{3}$ \\
$(\boldsymbol{\%})$ & $\mathbf{( \mathbf { 0 , 2 4 } \% )}$ & $\mathbf{( 5 , 3 2 \% )}$ & $\mathbf{( 3 , 8 7 \% )}$ & $\mathbf{( 2 1 , 0 6 \% )}$ & $\mathbf{( 5 1 , 8 1 \% )}$ & $\mathbf{( 1 6 , 9 4 \% )}$ & $(\mathbf{0 , 7 2 \% )}$ \\
\hline Homem & 1 & 13 & 12 & 43 & 118 & 41 & 1 \\
$\mathrm{n}=229$ & $(0.43 \%)$ & $(5,67 \%)$ & $(5,24 \%)$ & $(18,77 \%)$ & $(51,52 \%)$ & $(17,90 \%)$ & $(0,43 \%)$ \\
$(\%)$ & 9 & 4 & 44 & 96 & 29 & 2 \\
\hline $\begin{array}{c}\text { Mulher } \\
\text { n=184 }\end{array}$ & 0 & $(4,89 \%)$ & $(2,17 \%)$ & $(23,91 \%)$ & $(52,17 \%)$ & $(15,76 \%)$ & $(1,08 \%)$ \\
$(\%)$ & & & & & & & \\
\hline
\end{tabular}

Nota: A Tabela demonstra os dados gerais da amostra e a divisão por sexo segundo a doença de base.

De acordo com os regimes de condicionamentos utilizados para o TCTH autólogo, dos 413 prontuários analisados $148(35,83 \%)$ compreendiam o protocolo BEAM (convencional e com dose aumentada - BEAM 400), 147 (35,59\%) compreendiam o protocolo MEL, 88 (21,30\%) compreendiam o protocolo BU+MEL, $15(3,63 \%)$ compreendiam o protocolo ICE e $15(3,63 \%)$ compreendiam outros protocolos (não descriminados nos prontuários). Os regimes de condicionamento relatados nos 229 prontuários de pacientes masculinos foram: 79 casos com carmustina, etoposide, citarabina e melfalano (BEAM), 41 casos com bussulfano e melfalano (BU+MEL), 11 casos com ifosfamida, carboplatina, etoposide (ICE), 89 casos com melfalano (MEL), 9 casos com outros tipos de condicionamento não especificados nos prontuários e nos 184 casos prontuários de pacientes do sexo feminino, 69 casos com carmustina, etoposide, citarabina e melfalano (BEAM), 47 casos com bussulfano e melfalano (BU+MEL), 4 casos com ifosfamida, carboplatina, e toposide (ICE), 58 casos com melfalano (MEL), 6 casos com outros tipos de condicionamento não especificados 
nos prontuários. A Tabela 6 mostra os resultados do regime de condicionamento: dados gerais e divisão de acordo com o sexo.

Tabela 6: Regime de condicionamento: dados gerais e divisão de acordo com o sexo.

\begin{tabular}{|c|c|c|c|c|c|}
\cline { 2 - 6 } \multicolumn{1}{c|}{} & BEAM & BU+MEL & ICE & MEL & Outros \\
\hline $\mathbf{n = 4 1 3}(\%)$ & $\mathbf{1 4 8}$ & $\mathbf{8 8}$ & $\mathbf{1 5}$ & $\mathbf{1 4 7}$ & $\mathbf{1 5}$ \\
\hline Homem & 79 & 41 & 11 & 89 & $\mathbf{( 3 , 6 3 \% )}$ \\
$\mathrm{n}=229(\%)$ & $(34,49 \%)$ & $(17,90 \%)$ & $(4,80 \%)$ & $(38,86 \%)$ & $(3,93 \%)$ \\
\hline Mulher & 69 & 47 & 4 & 58 & 6 \\
$\mathrm{n}=184(\%)$ & $(37,50 \%)$ & $(25,54 \%)$ & $(2,17 \%)$ & $(31,52 \%)$ & $(3,26 \%)$ \\
\hline
\end{tabular}

Nota: A Tabela demonstra os dados gerais da amostra e a divisão por sexo segundo o regime de condicionamento.

Em relação à incidência global de mucosite oral nos pacientes submetidos ao TCTH autólogo, dos 413 prontuários analisados, $210(50.85 \%)$ dos pacientes não desenvolveram mucosite oral, enquanto 203 (49,15\%) desenvolveram algum grau de mucosite oral. Destes 413 pacientes que desenvolveram mucosite oral, $161(38,98 \%)$ apresentaram mucosite leve (Graus 1 e 2), enquanto $42(10,17 \%)$ apresentaram mucosite grave (Graus 3 e 4). Do total de 413 pacientes, foram 229 (55,45\%) de homens e 184 mulheres (44,55\%). Para os homens foi observado que $126(55,02 \%)$ pacientes não desenvolveram e 103(44,98\%) desenvolveram mucosite oral. Para mulheres foram observados, $84(45,65 \%)$ pacientes que não desenvolveram e 100 
$(54,35 \%)$ que desenvolveram mucosite oral $(\mathrm{p}=0.05)$. Os homens, em relação às mulheres, apresentaram um maior número de casos de mucosite.

Dos 203 pacientes que desenvolveram mucosite, 103 (50,74\%) foram homens e $100(49,26 \%)$ mulheres. Para os homens, 79 (76,70\%) portadores de mucosite graus 1 e 2, enquanto $24(23,30 \%)$ pacientes desenvolveram mucosite graus 3 e 4 . Para as mulheres, $82(82,00 \%)$ desenvolveram mucosite graus 1 e 2 , enquanto $18(18,00 \%)$ desenvolveram mucosite graus 3 e $4(\mathrm{p}=0.35)$. A Tabela 7 apresenta os dados referentes a incidência global da mucosite oral e a incidência por sexo.

Tabela 7: Incidência da mucosite oral (MO) global e de acordo com o sexo.

\begin{tabular}{|c|c|c|c|}
\hline Sexo & Sem MO & MO leve & MO grave \\
\hline N=413 & $\mathbf{2 1 0}$ & G1/G2 (\%) & G3/G4 (\%) \\
$(\boldsymbol{\%})$ & $\mathbf{( 5 0 , 8 5 \% )}$ & $\mathbf{( 3 8 , 9 8 \% )}$ & $\mathbf{1 6 1}$ \\
\hline Homem & 126 & 79 & 24 \\
$\mathrm{n}=229(\%)$ & $(55 \%)$ & $(34 \%)$ & $(11 \%)$ \\
\hline $\begin{array}{l}\text { Mulher } \\
\mathrm{n}=184(\%)\end{array}$ & $(45,5 \%)$ & $(44,5 \%)$ & $(10 \%)$ \\
\hline
\end{tabular}

Em relação ao regime de condicionamento, dos 148 prontuários de pacientes que foram submetidos ao condicionamento BEAM, 73 (49,3\%) casos não tiveram nenhum grau de mucosite oral (Grau 0), $75(50,7 \%)$ casos tiveram algum tipo de grau de mucosite oral (Graus 1, 2, 3 ou 4), 59 (40\%) casos tiveram mucosite leve (Grau 1 ou 2), $16(11 \%)$ casos tiveram mucosite oral grave (Grau 3 ou 4). Nos 88 prontuários de pacientes que foram submetidos ao condicionamento BU+MEL, 16 (18\%) casos não 
tiveram nenhum grau de mucosite oral (Grau 0), 72 (82\%) casos tiveram algum grau de mucosite oral (Graus 1, 2, 3 ou 4), 63 (72\%) casos tiveram mucosite leve (Grau 1 ou 2), $9(10,5 \%)$ tiveram mucosite oral grave (Grau 3 ou 4). Nos 15 prontuários de pacientes que foram submetidos ao condicionamento ICE, 12 (80\%) casos não tiveram nenhum grau de mucosite oral (Grau 0), 3 (20\%) casos tiveram algum grau de mucosite oral (Grau 1, 2, 3 ou 4), 1 (7\%) caso teve mucosite leve (Grau 1 ou 2), 2 (14\%) casos tiveram mucosite oral grave (Grau 3 ou 4). Nos 147 prontuários de pacientes que foram submetidos ao condicionamento MEL, 103 (70\%) casos não tiveram nenhum grau de mucosite oral (Grau 0), 44 (30\%) casos tiveram algum grau de mucosite oral (Grau 1, 2, 3 ou 4), 32 (22\%) casos tiveram mucosite leve (Grau 1 ou 2), 12 (8,5\%) casos tiveram mucosite oral grave (Grau 3 ou 4). Para os 15 prontuários de pacientes cujos condicionamentos não foram descritos nos prontuários, 6 (40\%) casos não tiveram nenhum grau de mucosite oral (Grau 0), 9 (60\%) casos tiveram algum grau de mucosite oral (Grau 1, 2, 3 ou 4), 6 (40\%) casos tiveram mucosite leve (Grau 1 ou 2), 3 (20\%) casos tiveram mucosite oral grave (Grau 3 ou 4). Quando comparada a incidência de mucosite oral correlacionando com os regimes de condicionamento notou-se que houve diferença estatística para a incidência de mucosite oral $(p=4,48 E-13)$ entre todos os regimes de condicionamento. Quando analisadas as frequências de mucosite oral de acordo com o regime de condicionamento, notou-se que a maior discrepância entre desenvolver e não desenvolver ocorreu nos casos dos pacientes submetidos ao regime de condicionamento BU/MEL e MEL. Quando excluídos os regimes de condicionamento BU/MEL e MEL da análise, notou-se que a incidência de mucosite nos regimes BEAM, ICE e outros não apresentaram diferença estatística $(p=0,06)$, considerando que o BU/MEL e o MEL foram os responsáveis pela significância estatística. Quando comparados os regimes de condicionamento BU/MEL com MEL 
notou-se que o regime BU/MEL apresentou maior incidência de mucosite oral $(\mathrm{p}=1,36 \mathrm{E}-14)$. A Tabela 8 apresenta os dados referentes à incidência da mucosite oral relacionada com o regime de condicionamento.

Tabela 8: Incidência da mucosite oral de acordo com os regimes de condicionamento.

\begin{tabular}{|l|c|c|c|c|c|}
\cline { 2 - 6 } \multicolumn{1}{l|}{} & & Sem MO & de MO & MO leve & MO Grave \\
& & G0 $(\%) *$ & G1/G2/G3/G4 & G1/G2 (\%)* & G3/G4 (\%)* \\
\hline BEAM & 148 & $73(49,3 \%)$ & $75(50,7 \%)$ & $59(40 \%)$ & $16(11 \%)$ \\
\hline BU+MEL & 88 & $16(18 \%)$ & $72(82 \%)$ & $63(72 \%)$ & $09(10,5 \%)$ \\
\hline ICE & 15 & $12(80 \%)$ & $03(20 \%)$ & $1(07 \%)$ & $2(14 \%)$ \\
\hline MEL & 147 & $103(70 \%)$ & $44(30 \%)$ & $32(22 \%)$ & $12(8,5 \%)$ \\
\hline Outros & 15 & $06(40 \%)$ & $9(60 \%)$ & $6(40 \%)$ & $3(20 \%)$ \\
\hline
\end{tabular}

MO: Mucosite Oral; G: Grau.

*Valores proporcionais aos pacientes que foram submetidos ao tipo de condicionamento. 
Figura 1: Frequência de mucosite oral por regime de condicionamento.

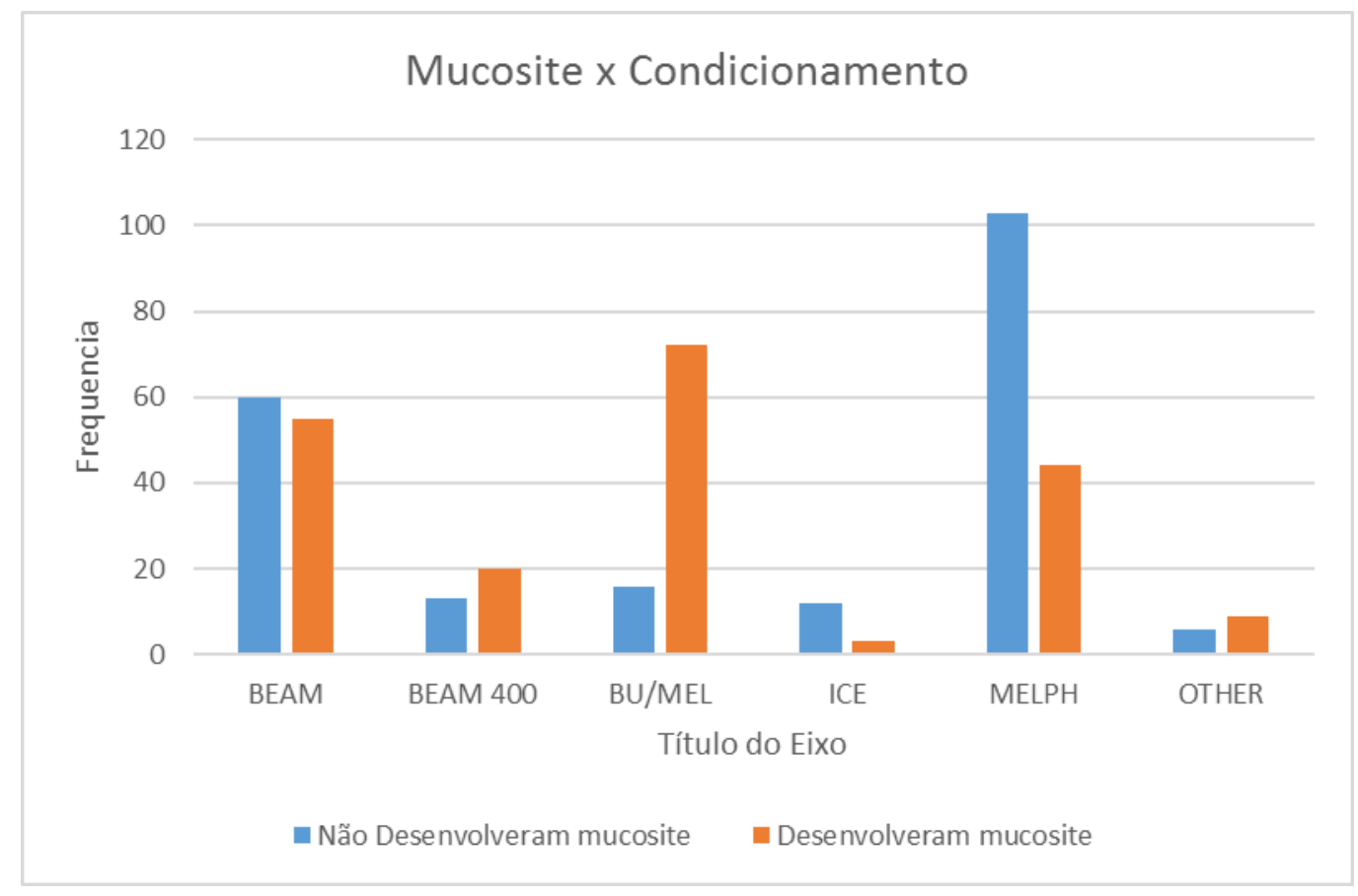

Figura 2: Frequência de mucosite oral por regime de condicionamento.

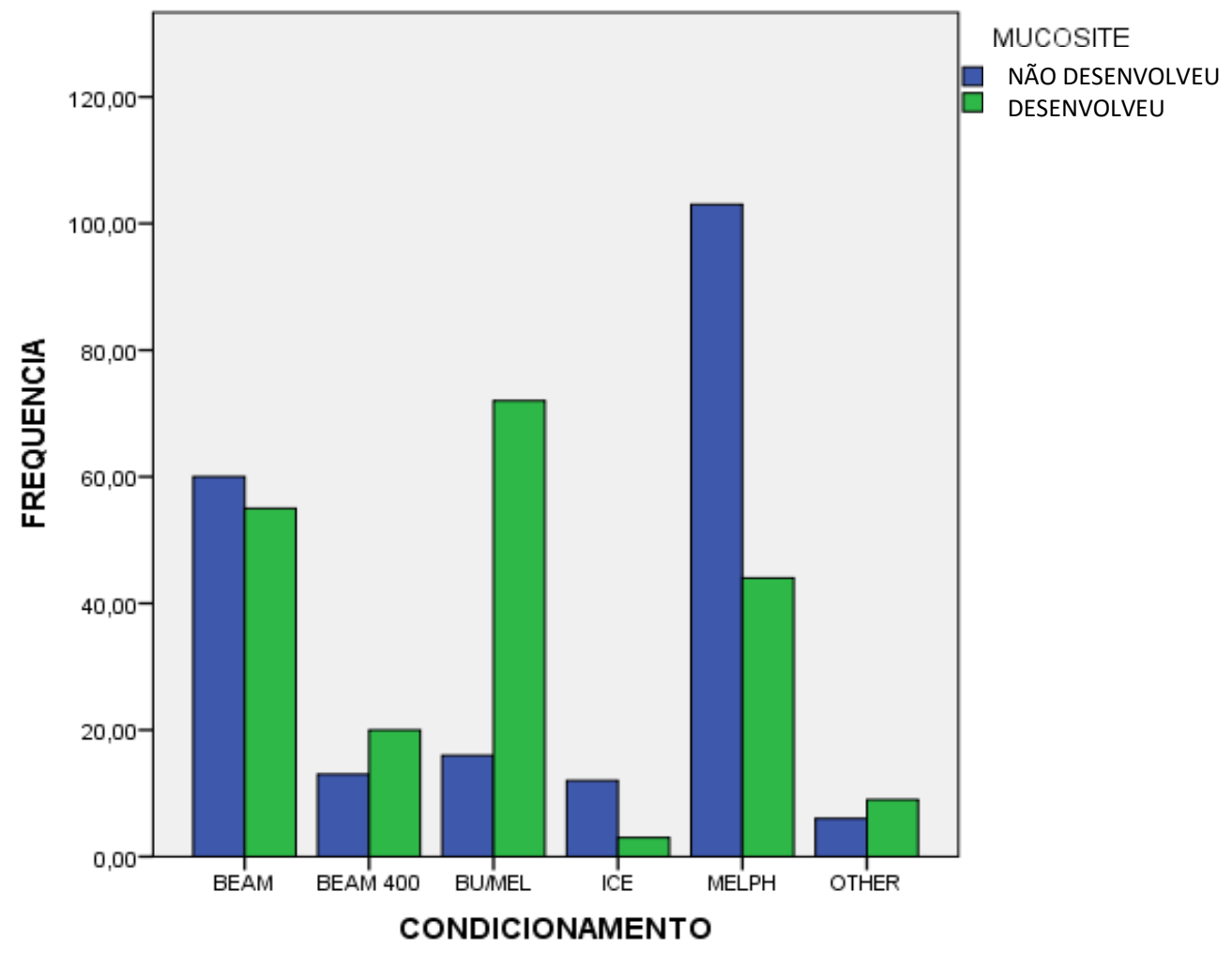


Figura 3: Frequência de mucosite oral por regime de condicionamento, excluindo BU/MEL e MEL.

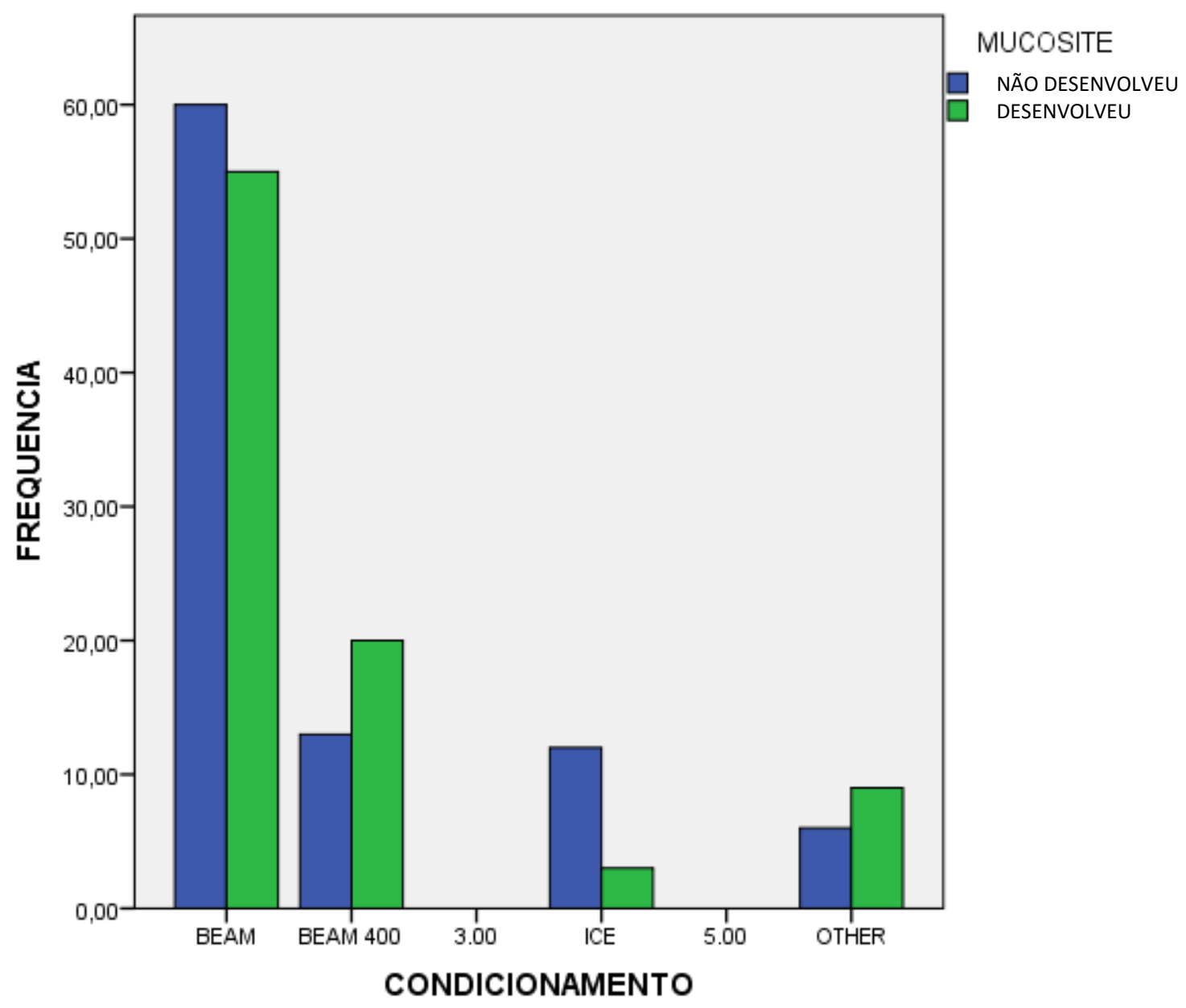


Figura 4: Frequência de mucosite oral por regime de condicionamento BU/MEL e MEL.

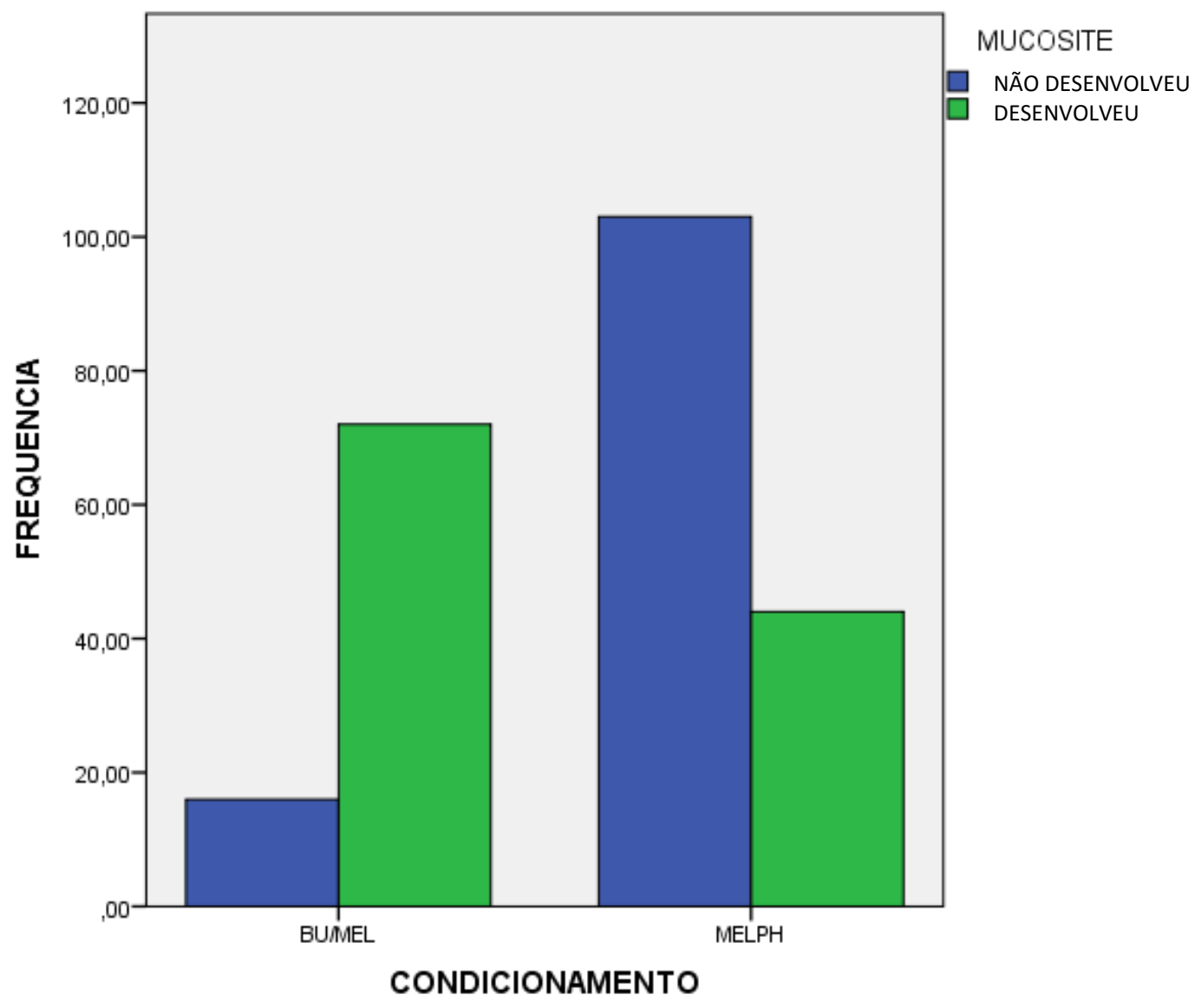

Em relação à doença de base, dos 413 prontuários de pacientes analisados, o único caso de leucemia linfóide aguda (LLA) desenvolveu mucosite oral grave (Grau 34). Nos casos de leucemia mieloide aguda (LMA), $3 / 22(13,63 \%)$ não desenvolveram mucosite oral (G0) e 19/22 (86,37\%) desenvolveram mucosite oral (G1-2-3-4), sendo que os casos que desenvolveram $\mathrm{MO}, 78,94 \%$ desenvolveram forma leve (G1-2) e 21,06\% desenvolveram forma grave (G3-4). Nos casos de tumor de células germinativas (TCG), 12/16 (75\%) não desenvolveram mucosite oral (G0) e 4/16 (25\%) desenvolveram mucosite oral (G1-2-3-4), sendo que os casos que desenvolveram MO, $50 \%$ desenvolveram forma leve (G1-2) e 50\% desenvolveram forma grave (G3-4). Nos casos de doença de Hodgkin (DH), 39/87 (45\%) não desenvolveram mucosite oral (G0) e 48/87 (55\%) desenvolveram mucosite oral (G1-2-3-4), sendo que os casos que 
desenvolveram MO, 72,91\% desenvolveram forma leve (G1-2) e 27,09\% desenvolveram forma grave (G3-4). Nos casos de linfoma não-Hodgkin (LNH), 37/70 $(52,85 \%)$ não desenvolveram mucosite oral (G0) e 33/70 (47,15\%) desenvolveram mucosite oral (G1-2-3-4), sendo que os casos que desenvolveram MO, 84,84\% desenvolveram forma leve (G1-2) e 15,16\% desenvolveram forma grave (G3-4). Nos casos de mieloma múltiplo (MM), 119/214 (55,60\%) não desenvolveram mucosite oral (G0) e 95/214 (44,40\%) desenvolveram mucosite oral (G1-2-3-4), sendo que os casos que desenvolveram MO, 82,10\% desenvolveram forma leve (G1-2) e 17,90\% desenvolveram forma grave (G3-4). Nos casos de outras doenças, 1/3 (33,34\%) não desenvolveu mucosite oral (G0) e 2/3 $(66,66 \%)$ desenvolveram mucosite oral (G1-2-34), sendo que os casos que desenvolveram MO foram 100\%. Quando comparados os pacientes que desenvolveram e não desenvolveram mucosite relacionados com as doenças de base notou-se que houve diferença estatística para a incidência de mucosite entre as doenças de base $(\mathrm{p}=0,002)$. Quando analisadas as frequências de mucosite oral de acordo com a doença de base notou-se que a maior discrepância entre desenvolver e não desenvolver ocorreu nos casos dos pacientes portadores de LMA (Figura 5). Para verificar se houve diferença na incidência de mucosite oral influenciada pelos casos de LMA, quando estes foram excluídos da análise, observou-se que não houve diferença estatística entre a incidência de mucosite nos pacientes portadores de MM, TCG, LLA, DH e NHD $(\mathrm{p}=0,18)$. A Tabela 9 apresenta os dados referentes à incidência da mucosite oral relacionada com a doença de base. 
Tabela 9: Incidência da mucosite oral relacionada com a doença de base.

\begin{tabular}{|l|c|c|c|c|c|}
\cline { 2 - 6 } \multicolumn{1}{c|}{} & $\mathbf{n = 4 1 3}$ & Sem MO & Qualquer tipo de MO & MO leve & MO Grave \\
\hline LLA & 1 & 0 & G1/G2/G3/G4 $(\%) *$ & G1/G2 $(\%) *$ & G3/G4 (\%)* \\
\hline LMA & 22 & $3(13,63 \%)$ & $1(100 \%)$ & 0 & $1(100 \%)$ \\
\hline TCG & 16 & $12(75 \%)$ & $4(25 \%)$ & $2(50 \%)$ & $2(50 \%)$ \\
\hline HD & 87 & $39(45 \%)$ & $48(55 \%)$ & $35(72,91 \%)$ & $13(27,09 \%)$ \\
\hline MM & 214 & $119(55,60 \%)$ & $95(44,40 \%)$ & $78(82,10 \%)$ & $17(17,90 \%)$ \\
\hline LNH & 70 & $37(52,85 \%)$ & $33(47,15 \%)$ & $28(84,84 \%)$ & $05(15,16 \%)$ \\
\hline Outros & 3 & $1(33,34 \%)$ & $2(66,66 \%)$ & $2(100 \%)$ & 0 \\
\hline
\end{tabular}

MO: Mucosite Oral; G: Grau.

*Valores proporcionais aos pacientes e suas doenças de base.

Figura 5: Frequência de mucosite oral relacionado com doença de base.

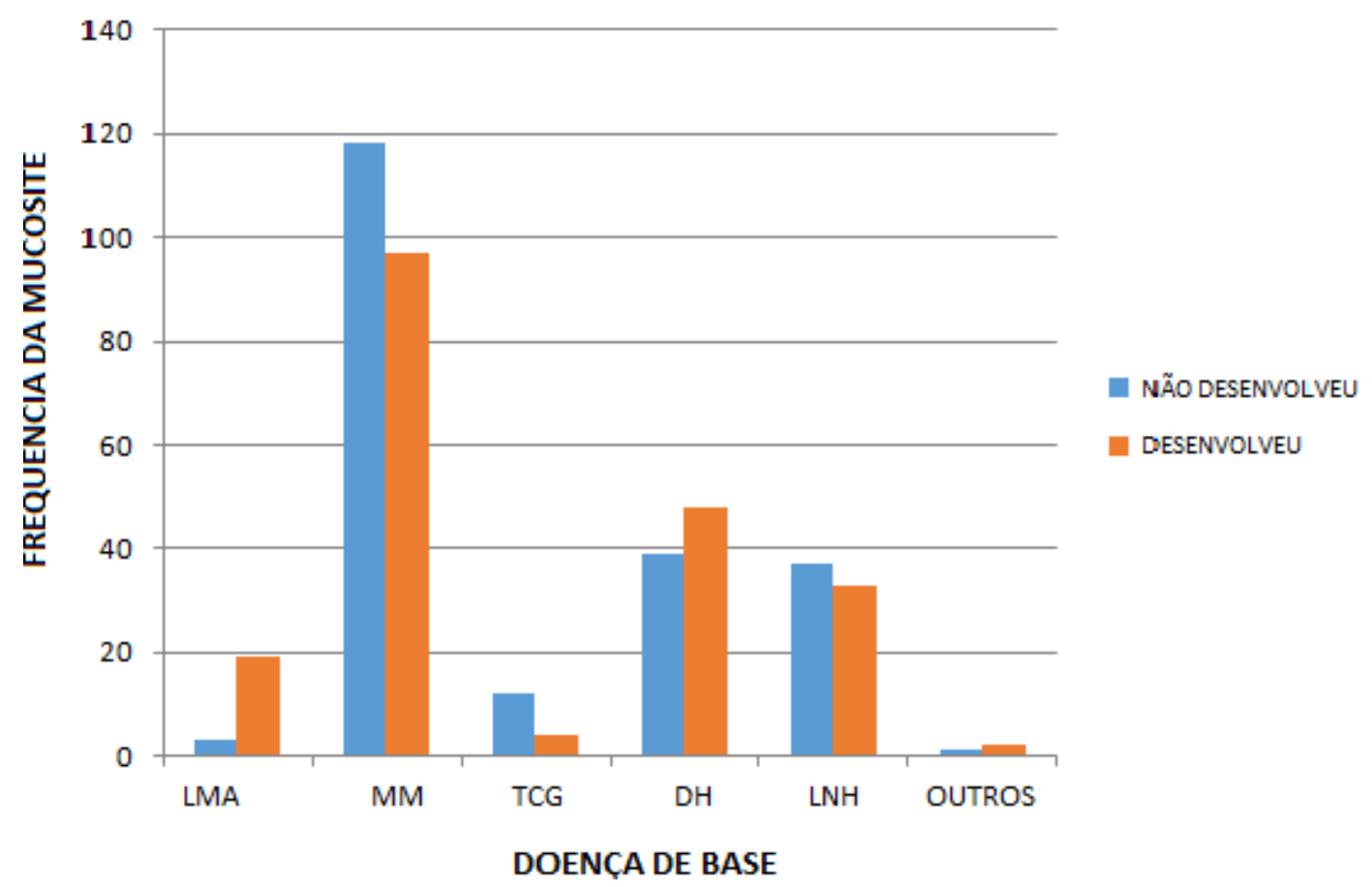




\section{DISCUSSÃO}




\section{DISCUSSÃO}

Foram avaliadas neste estudo retrospectivo as variáveis que poderiam estar associadas ao desenvolvimento da mucosite oral no transplante de células tronco hematopoiéticas autólogo com uma casuística homogênea em relação ao tipo de transplante baseada em 413 prontuários de pacientes consecutivos submetidos ao transplante autólogo de células tronco hematopoiéticas. Na literatura, a maioria dos trabalhos relatam que o TCTH alogênico apresenta maior incidência de mucosite oral e aqueles que avaliaram o TCTH autólogo são escassos e com amostras pequenas. Os trabalhos que apresentam amostras expressivas não são homogêneos em relação ao tipo de transplante.

Embora apresentando menor risco de toxicidade na mucosa oral durante o transplante autólogo, este trabalho mostrou que aproximadamente metade dos pacientes apresentaram algum grau de mucosite oral e, destes, 10,17\% apresentaram mucosite grave. Estes dados mostram a necessidade de protocolos de cuidados bucais individualizados.

Em relação à qualidade de vida, os pacientes com piores condições de saúde bucal apresentam um impacto negativo em sua qualidade de vida levando a maior preocupação, stress e dificuldade na sua relação interpessoal (Tinoco-Araújo, 2015). Embora o objetivo deste trabalho não tenha sido avaliar a qualidade de vida, sabe-se que a condição de saúde bucal apresenta relação direta com a incidência da mucosite oral no transplante autólogo (Coracin, 2013) e que o protocolo de cuidados bucais prétransplante reduz o tempo de duração e gravidade da mucosite oral (Santos, 2011). Os resultados deste trabalho sugerem que os pacientes submetidos ao TCTH autólogo devam ser submetidos a protocolos de cuidados bucais intensivos pré-transplante, pois a 
condição da saúde bucal está diretamente relacionada à incidência da mucosite oral e, consequentemente, com impacto negativo da qualidade de vida $(50,85 \%$ apresentaram algum tipo de mucosite oral e 10,17\% apresentaram mucosite grave). Estes protocolos devem objetivar, principalmente, os pacientes do sexo masculino e, quando estratificado por faixa de idade, as pacientes do sexo feminino jovens, com idade mediana de 29 anos.

A mucosite é um efeito grave e dose-limitante do tratamento antineoplásico, cujas lesões ulceradas, quando ocorrem, apresentam grande impacto na morbidade e mortalidade dos pacientes por apresentar dor, restrição alimentar e funcionando como porta de entrada para infecções originadas da mucosa bucal (Sonis, 2004). Neste estudo foi encontrada a presença de mucosite oral grave, graus 3 e 4, em 10,17\% dos pacientes. Segundo o CIBMTR (Center for International Blood and Marrow Transplant Research) as indicações mais comuns para o TCTH incluem o mieloma múltiplo e os linfomas representando, juntos, 52\% dos transplantes realizados até 2014 (Pasquini, 2015). Neste estudo, dos 413 prontuários de pacientes analisados, 89,83\% dos transplantes foram realizados em pacientes portadores de mieloma múltiplo e linfomas sendo que, destes, $47,43 \%$ apresentaram algum grau de mucosite oral $(9,5 \%$ desenvolveram mucosite grave).

Vários estudos mostraram que o sexo feminino apresenta risco maior de desenvolver mucosite (Stein, 1995; Zalcberg, 1998; Sloan, 2000; Vokurka, 2006). Neste estudo, os resultados da idade dos pacientes em relação ao desenvolvimento da mucosite oral mostraram não haver diferença estatística entre os escores médios das idades nos pacientes que não desenvolveram e desenvolveram qualquer grau de mucosite. Porém, quando avaliados apenas os pacientes do sexo masculino e a incidência de mucosite oral não houve diferença estatística. Entretanto, pacientes do 
sexo feminino apresentaram maior incidência de mucosite oral e a ocorrência de mucosite grau 3 apresentou idade média menor que os pacientes portadores dos graus 1 e 4 .

O impacto significativo na qualidade de vida dos pacientes durante o transplante ocorre devido ao condicionamento quimioterápico com uso de altas doses de melfalano (Harris, 2009). Outro regime de condicionamento quimioterápico realizado nos TCTH que também apresenta alta incidência de mucosite oral é o esquema com bussulfano associado ao melfalano (BU+MEL) (Blanes, 2015) e, também, o regime de condicionamento quimioterápico contendo carmustina, etoposide, citarabina e melfalano (BEAM) (Blijlevens, 2005; Jones, 2006). Neste estudo, dos 413 prontuários de pacientes analisados, os condicionamentos quimioterápicos BEAM, BU+MEL e MEL correspondem a 92,74\% dos esquemas de regime de condicionamento utilizados e, destes, 46,25\% apresentaram algum grau de mucosite oral (9\% desenvolveram mucosite grave). Quando comparada a incidência de mucosite oral de acordo com os regimes de condicionamento, notou-se que houve diferença estatística para a incidência de mucosite oral entre todos os regimes de condicionamento. Quando analisadas as frequências de mucosite oral de acordo com o regime de condicionamento, a maior discrepância entre desenvolver e não desenvolver mucosite ocorreu nos casos dos pacientes submetidos ao regime de condicionamento BU/MEL e MEL. Quando excluídos os regimes de condicionamento BU/MEL e MEL da análise, a incidência de mucosite nos regimes BEAM, ICE e outros não apresentaram diferença estatística. Os resultados deste estudo mostraram que o regime de condicionamento BU/MEL apresentou maior incidência de mucosite oral.

A mucosite oral e gastrointestinal são as toxicidades não hematológicas mais frequentes no transplante autólogo (Anastasia, 2009; Jagasia, 2011). Em um estudo 
realizado com pacientes submetidos a transplante autólogo a incidência da mucosite oral foi de $69 \%$ em uma coorte compreendendo pacientes portadores de MM, DH, LNH e LMA (Barban, 2014). Neste estudo, quando comparados os pacientes que desenvolveram e não desenvolveram mucosite relacionados com as doenças de base, notou-se que houve diferença estatística para a incidência de mucosite entre as doenças de base e que os pacientes portadores de LMA apresentaram maior incidência de mucosite, comparados com os pacientes portadores de MM, TCG, LLA, DH e LNH.

Os resultados deste estudo retrospectivo de 413 prontuários de pacientes submetidos ao transplante autólogo mostraram que a incidência de mucosite foi maior em pacientes do sexo masculino e nos pacientes do sexo feminino com idade média de 29 anos, nos pacientes submetidos ao regime de condicionamento BU/MEL e naqueles pacientes portadores de LMA. Estes dados nos fornecem novas informações para repensarmos sobre o planejamento de protocolos de cuidados bucais de forma individualizada nos pacientes que serão submetidos ao transplante de células tronco hematopoiéticas autólogo, tendo como foco a prevenção, o controle e o tratamento da mucosite oral. 
CONCLUSÃO 


\section{CONCLUSÃO}

Os dados deste estudo permitiram concluir que a incidência da mucosite oral apresentou:

- Maior incidência global em pacientes do sexo masculino;

- Pacientes do sexo feminino com idade média de 29 anos quando avaliados por sexo e estratificado em idades;

- Maior incidência quando submetido ao regime de condicionamento combinando bussulfano e melfalano (BU/MEL);

- Maior incidência nos pacientes portadores de leucemia mieloide aguda (LMA). 
ANEXO 


\title{
ANEXO
}

\author{
PARECER DE APROVAÇÃO - COMISSÃo de ÉTICA PARA ANÁlISE dE \\ PROJETOS DE PESQUISA - CAPPESQ - HC/FMUSP (PAG.1)
}

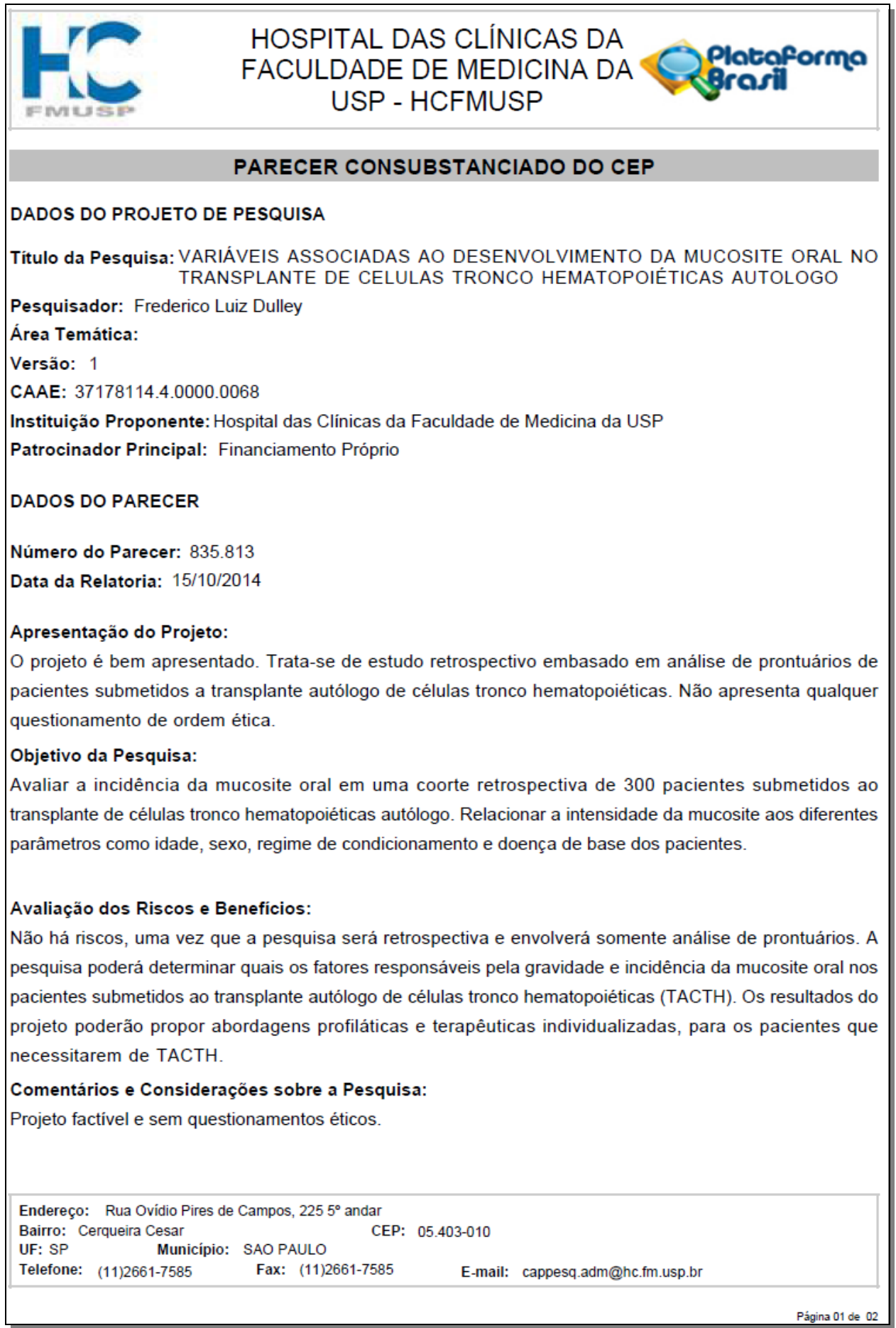




\title{
ANEXO
}

\author{
PARECER DE APROVAÇÃo - COMISSÃo DE ÉTICA PARA ANÁlISE de \\ PROJETOS DE PESQUISA - CAPPESQ - HC/FMUSP (PAG.2)
}

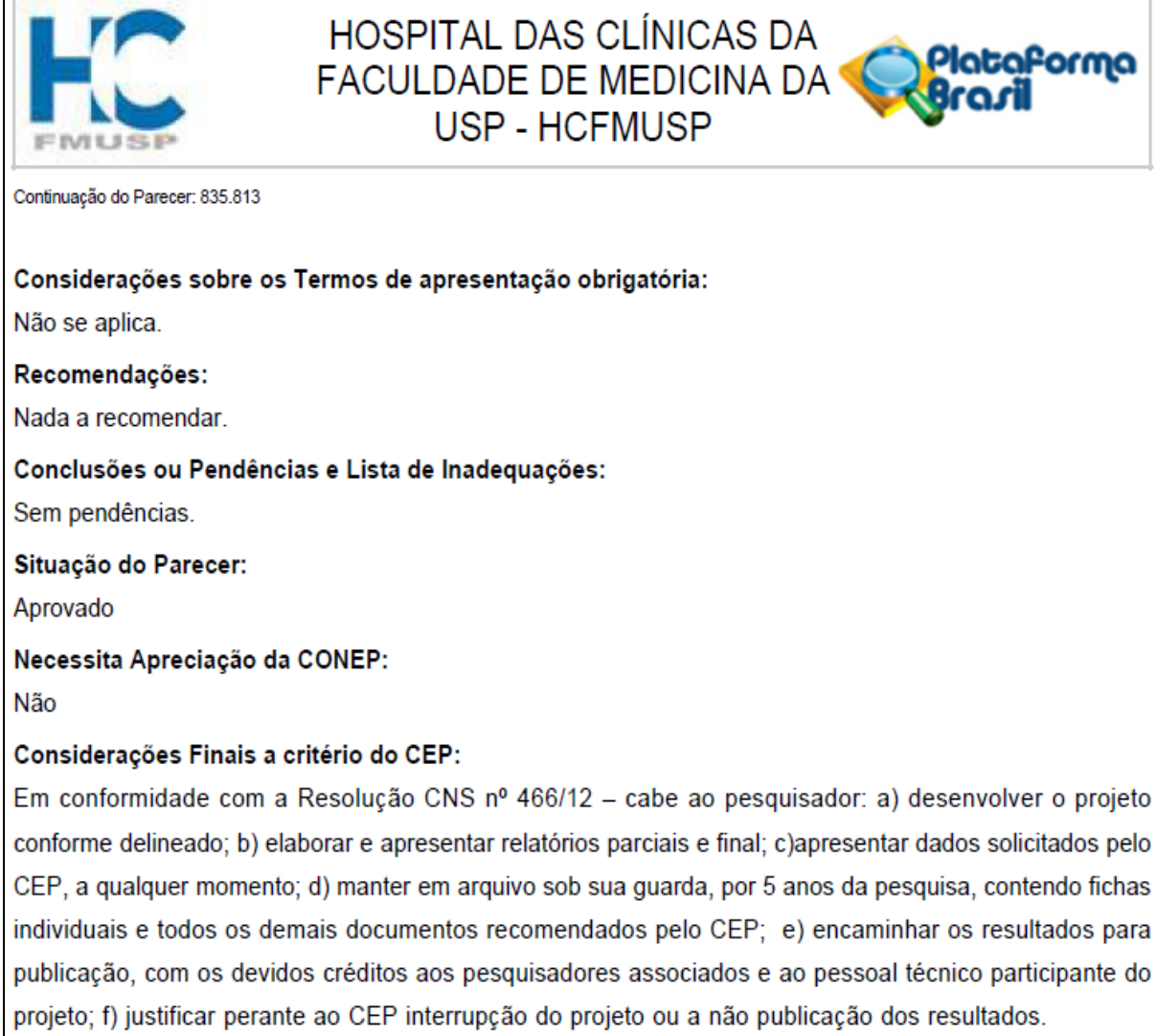


REFERÊNCIAS BIBLIOGRÁFICAS 


\section{REFERÊNCIAS BIBLIOGRÁFICAS}

Amos TA, Gordon MY. Sources of human hematopoietic stem cells for transplantation-a review. Cell Transplant. 1995;4(6):547-69.

Anastasia A, Giglio F, Mazza R, Sarina B, Todisco E, Bramanti S, et al. Early discharge after high-dose melphalan and peripheral blood stem cell reinfusion in patients with hematological and non-hematological disease. Leuk Lymphoma. 2009;50:80-4.

Anderlini P, Donato M, Chan KW, Huh YO, Gee AP, Lauppe MJ et al. Allogeneic blood progenitor cell collection in normal donors after mobilization with filgrastim: the M.D. Anderson Cancer Center experience. Transfusion. 1999;39(6):555-60.

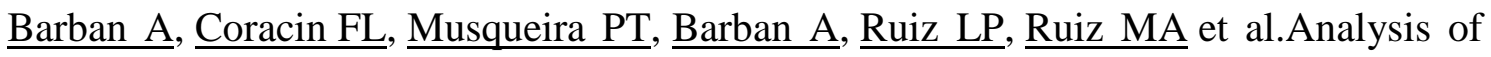
the feasibility of early hospital discharge after autologous hematopoietic stem cell transplantation and the implications to nursing care. Rev Bras Hematol Hemoter. 2014 Jul-Aug;36(4):264-8.

Bhatia S, Francisco L, Carter A, Sun CL, Baker KS, Gurney JG et al. Late mortality after allogeneic hematopoietic cell transplantation and functional status of longterm survivors: report from the Bone Marrow Transplant Survivor Study. Blood. 2007;110(10):3784-92. Epub 2007 Aug 1. 
Blanes M, González JD, Lahuerta JJ, Ribas P, Lorenzo I, Boluda B et al. Bortezomibbased induction therapy followed by intravenous busulfan-melphalan as conditioning regimen for patients with newly diagnosed multiple myeloma. Leuk Lymphoma. 2015; 56(2):415-9.

Blijlevens N, Donnelly SP, De Pauw BE. Inflammatory response to mucosal barrier injury after myeloablative therapy in allogenic stem cell transplant recipients. Bone Marrow Transplant 2005; 36:703-7.

Bonassa EMA, Mancusi FCM, Transplante de medula óssea e de células troncohematopoiéticas. In: Bonassa EMA, Gato MIR, editoras. Terapêutica oncológica para enfermeiros e farmacêuticos. 4 Ed. São Paulo: Atheneu; 2012. Cap 9, p.489517.

Bueno ND, Dulley FL, Saboya R, Amigo Filho JU, Coracin FL, Chamone D de A. Busulfan and melphalan as conditioning regimen for allogeneic hematopoietic stem cell transplantation in acute myeloid leukemia in first complete remission. Rev Bras Hematol Hemoter. 2011; 33(3):179-84.

Coracin FL, Santos PS, Gallottini MH, Saboya R, Musqueira PT, Barban A et al. Oral health as a predictive factor for oral mucositis. Clinics (Sao Paulo). 2013;68(6):792-6. 
Cox GJ, Matsui SM, Lo RS, Hinds M, Bowden RA, Hackman RC et al. Etiology and outcome of diarrhea after marrow transplantation: a prospective study. Gastroenterology. 1994;107:1398-1407.

Culy CR, Spencer CM. Amifostine: an update on its clínical status as a cytoprotectant in patients with cancer receiving chemotherapy or radiotherapy and its potential therapeutic application in myelodysplastic syndrome. Drugs. 2001;61(5):641-84.

Dörr W, Spekl K, Martin M. Radiation-induced oral mucositis in mice: strain differences. Cell Prolif. 2002; 35 Suppl 1:60-7.

Durey K, Patterson H, Gordon K. Dental assessment prior to stem cell transplant: treatment need and barriers to care. Br Dent J. 2009; 206(9):E19; discussion 478-9.

Epstein JB, Schubert MM. Managing pain in mucositis. Semin Oncol Nurs. 2004; 20:30-37.

Gaté L, Paul J, Ba GN, Tew KD, Tapiero H. Oxidative stress induced in pathologies: the role of antioxidants. Biomed Pharmacother. 1999;53 (4):169-80.

Harris DJ and Eilers JG. Mucositis. In: Eaton LH and Tipton JM (eds) Putting evidence into practice: improving oncology patient outcomes. Pittsburgh: Oncology Nursing Society, 2009, 193-214. 
Hickman RO, Buckner CD, Clift RA, Sanders JE, Stewart P, Thomas ED. A modified right atrial catheter for access to the venous system in marrow transplant recipients. Surg Gynecol Obstet. 1979; 148(6):871-5.

Jagasia MH, Savani BN, Neff A, Dixon S, Chen H, Pickard AS. Outcome, toxicity profile and cost analysis of autologous stem cell mobilization. Bone Marrow Transplant. 2011;46:1084-8.

Jones J, Avritscher EB, Cooksley CD, Michelet M, Bekele BN, Elting LS. Epidemiology of treatment-associated mucosal injury after treatment with newer regimens for lymphoma, breast, lung, or colorectal cancer. Support Care Cancer 2006;14:505-15.

Jones JA, Qazilbash MH, Shih YC, Cantor SB, Cooksley CD, Elting LS. In-hospital complications of autologous hematopoietic stem cell transplantation for lymphoid malignancies: clínical and economic outcomes from the Nationwide Inpatient Sample. Cancer. 2008; 112(5):1096-105.

Kühne A, Sezer O, Heider U, Meineke I, Muhlke S, Niere W et al. Population pharmacokinetics of melphalan and glutathione S-transferase polymorphisms in relation to side effects. Clin Pharmacol Ther. 2008; 83(5):749-57. Epub 2007 Oct 3.

Langner S, Staber P, Schub N, Gramatzki M, Grothe W, Behre G et al. Palifermin reduces incidence and severity of oral mucositis in allogeneic stem-cell transplant recipients. Bone Marrow Transplant. 2008; 42:275-279. 
Li HW, Sykes M. Emerging concepts in haematopoietic cell transplantation. Nat Rev Immunol. 2012; 12(6):403-16.

Maddens S, Charruyer A, Plo I, Dubreuil P, Berger S, Salles B et al. Kit signaling inhibits the sphingomyelin-ceramide pathway through PLC gamma 1:implication in stem cell factor radioprotective effect. Blood. 2002; 100(4):1294-301.

Neitzert CS, Ritvo P, Dancey J, Weiser K, Murray C, Avery J. The psychosocial impact of bone marrow transplantation: a review of the literature. Bone Marrow Transplant. 1998; 22(5):409-22.

Pasquini MC, Zhu X. Current use and outcome of hematopoietic stem cell transplantation: CIBMTR Summary Slides, 2015. Available at: http://www.cibmtr.org

Rebeiro P, Moore J. The role of autologous haemopoietic stem cell transplantation in the treatment of autoimmune disorders. Intern Med J. 2016; 46(1):17-28.

Rosenbeck LL, Srivastava S, Kiel PJ. Peripheral blood stem cell mobilization tactics. Ann Pharmacother. 2010; 44(1):107-16.

Roy J, Snover D, Weisdorf S, Mulvahill A, Filipovich A, Weisdorf D. Simultaneous upper and lower endoscopic biopsy in the diagnosis of intestinal graft-versus-host disease. Transplantation. 1991; 51: 642-646. 
Ruescher TJ, Sodeifi A, Scrivani SJ, Kaban LB, Sonis ST.The impact of mucositis on alpha-hemolytic streptococcal infection in patients undergoing autologous bone marrow transplantation for hematologic malignancies. Cancer. 1998; 82(11):227581.

Santos GW. History of bone marrow transplantation. Clin. Hematol. 1983;2(3):611-639.

Santos PS, Coracin FL, Barros JC, Dulley FL, Nunes FD, Magalhães MG. Impact of oral care prior to HSCT on the severity and clínical outcomes of oral mucositis. Clin Transplant. 2011; 25(2):325-8.

Sloan JA, Loprinzi CL, Novotny PJ, et al: Sex differences in fluorouracil-induced stomatitis. J Clin Oncol. 2000; 18:412-420.

Socié G, Stone JV, Wingard JR, Weisdorf D, Henslee-Downey PJ, Bredeson C et al. Long-term survival and late deaths after allogeneic bone marrow transplantation. Late Effects Working Committee of the International Bone Marrow Transplant Registry. N Engl J Med. 1999; 341(1):14-21.

Sonis S, Clark J. Prevention and management of oral mucositis induced by antineoplastic therapy. Oncology (Williston Park). 1991; 5(12):11-8. 
Sonis ST, Elting LS, Keefe D, Peterson DE, Schubert M, Hauer-Jensen M et al. Perspectives on cancer therapy-induced mucosal injury: pathogenesis, measurement, epidemiology, and consequences for patients. Mucositis Study Section of the Multinational Association for Supportive Care in Cancer; International Society for Oral Oncology. Cancer. 2004; 100(9 Suppl):1995-2025.

Sonis ST, Oster G, Fuchs H, Bellm L, Bradford WZ, Edelsberg J et al. Oral mucositis and the clínical and economic outcomes of hematopoietic stem-cell transplantation. J Clin Oncol. 2001; 19(8):2201-5.

Sonis ST. Mucositis as a biological process: a new hypothesis for the development of chemotherapy-induced stomatotoxicity. Oral Oncol. 1998; 34(1):39-43.

Stein BN, Petrelli NJ, Douglass HO, et al: Age and sex are independent predictors of 5fluorouracil toxicity: Analysis of a large scale phase III trial. Cancer.1995; 75:1117.

Storb R. Preparative regimens for patients with leukemias and severe aplastic anemia (overview): biological basis, experimental animal studies and clínical trials at the Fred Hutchinson Cancer Research Center. Bone Marrow Transplant. 1994;14 Suppl $4: S 1-3$.

Thomas ED, Storb R, Clift RA, Fefer A, Johnson FL, Neiman PE et al. Bone marrow transplantation. N Engl. J. Med. 1975;292:832-843. 
Thomas ED, Storb R, Clift RA, Fefer A, Johnson FL, Neiman PE et al. Bone marrow transplantation. N Engl. J. Med. 1975; 292:832-843.

Thomas ED, Storb R. Technique for human marrow grafting. Blood. 1970; 36(4):50715.

Tinoco-Araujo JE, Orti-Raduan ES, Santos D, Colturato VA, Souza MP, Mauad MA et al. Oral health-related quality of life before hematopoietic stem cell transplantation. Clin Oral Investig. 201; 19(9):2345-9.

Vera-Llonch M, Oster G, Ford CM, Lu J, Sonis S. Oral mucositis and outcomes of allogeneic hematopoietic stem-cell transplantation in patients with hematologic malignancies. Support Care Cancer. 2007;15:491-496.

Vokurka S, Bystricka E, Koza V, et al: Higher incidence of chemotherapy induced oral mucositis in females: A supplement of multivariate analysis to a randomized multicentre study. Support Care Cancer. 2006; 14: 974-976.

Weaver CH, Schwartzberg L, Zhen B, Mangum M, Leff R, Tauer K et al. High-dose chemotherapy and peripheral blood stem cell infusion in patients with nonHodgkins lymphoma: results of outpatient treatment in community cancer center. Bone Marrow Transplant. 1997; 20: 753-60. 
Weisdorf DJ, Snover DC, Haake R, Miller WJ, McGlave PB, Blazar B et al. Acute upper gastrointestinal graft-versus-host disease: clínical significance and response to immunosuppressive therap. Blood. 1990;76:624-629.

Westermann AM, Holtkamp MM, Linthorst GA, van Leeuwen L, Willemse EJ, van Dijk WC et al. At home management of aplastic phase following high-dose chemotherapy with stem-cell rescue for hematological and non-hematological malignancies. Ann Oncol. 1999; 10(5):511-7.

Wingard JR, Santos GW, Saral R. Differences between first and subsequent fevers during prolonged neutropenia. Cancer. 1987; 59(4):844-9.

World Health Organization. Handbook for Reporting Results of Cancer Treatment. Geneva, Switzerland: World Health Organization; 1979. pp. 15-22.

Zalcberg J, Kerr D, Seymour L, et al: Haematological and non-haematological toxicity after 5-fluorouracil and leucovorin in patients with advanced colorectal cancer is significantly associated with gender, increasing age and cycle number: Tomudex International Study Group. Eur J Cancer. 1998; 34:1871-1875. 